\title{
Zinc-Based Curing Activators: New Trends for Reducing Zinc Content in Rubber Vulcanization Process
}

\author{
Silvia Mostoni ${ }^{\circledR}$, Paola Milana, Barbara Di Credico®, Massimiliano D’Arienzo and \\ Roberto Scotti * \\ Department of Materials Science, INSTM, University of Milano Bicocca, Via Roberto Cozzi 55, 20125 Milano, Italy \\ * Correspondence: roberto.scotti@unimib.it; Tel.: +39-0264485133
}

Received: 10 July 2019; Accepted: 1 August 2019; Published: 2 August 2019

check for updates

\begin{abstract}
The efficiency of sulfur vulcanization reaction in rubber industry is generally improved thanks to the combined use of accelerators (as sulphenamides), activators (inorganic oxides), and co-activators (fatty acids). The interaction among these species is responsible for the formation of intermediate metal complexes, which are able to increase the reactivity of sulfur towards the polymer and to promote the chemical cross-links between the rubber chains. The high number of species and reactions that are involved contemporarily in the process hinders the complete understanding of its mechanism despite the long history of vulcanization. In this process, $\mathrm{ZnO}$ is considered to be the most efficient and major employed activator and zinc-based complexes that formed during the first steps of the reaction are recognized to play a main role in determining both the kinetic and the nature of the cross-linked products. However, the low affinity of $\mathrm{ZnO}$ towards the rubber entails its high consumption (3-5 parts per hundred, phr) to achieve a good distribution in the matrix, leading to a possible zinc leaching in the environment during the life cycle of rubber products (i.e., tires). Thanks to the recent recognition of $\mathrm{ZnO}$ ecotoxicity, especially towards the aquatic environment, these aspects gain a critical importance in view of the urgent need to reduce or possibly substitute the $\mathrm{ZnO}$ employed in rubber vulcanization. In this review, the reactivity of $\mathrm{ZnO}$ as curing activator and its role in the vulcanization mechanism are highlighted and deeply discussed. A complete overview of the recent strategies that have been proposed in the literature to improve the vulcanization efficiency by reducing the amount of zinc that is used in the process is also reported.
\end{abstract}

Keywords: zinc oxide; vulcanization; activator; zinc complexes; rubber; reinforcing filler

\section{Introduction}

$\mathrm{ZnO}$ is currently used in several products, including plastics, glass and ceramics, paints, batteries, fire retardants, cosmetics, and sunscreens [1,2]. Its semiconducting properties (band gap equal to $3.37 \mathrm{eV}$ ), near UV emission, transparent conductivity, and piezoelectricity also make it attractive for many electronic applications, as sensors, solar voltaic, and transducers [3-5]. Besides, ZnO is largely used in heterogeneous catalysis, both as support and active phase for reactions, such as methanol synthesis [6-8], water gas shift reaction (WGSR) [9-12], methanol steam reforming [13,14], and the photocatalytic degradation of organic environmental pollutants $[15,16]$.

One of the main applications of $\mathrm{ZnO}$ relies on the rubber industry as chemical activator of the vulcanization process. In fact, more than $50 \%$ of the $\mathrm{ZnO}$ global annual production (25 million tons reported in 2010 [17]) is used in rubber manufacturing [17-19] with tires production comprising its primary destination $[20,21]$.

Vulcanization is a consolidated large-scale process to cross-link rubber chains, forming a three-dimensional network, which provides mechanical properties, such as elasticity and tensile 
strength. It is based on the thermal formation, in the presence of sulfur, of mono-, bi-, and poly-sulfide bridges between the polymer chains. Vulcanization was originally discovered by Goodyear in 1839 [22]. Right after, additives, such as accelerators [23], activators [24,25], and co-activators, have been used to improve the processability, vulcanization rate, and cross-linking efficiency, in order to fulfill productivity requirements, while reducing the energy and time consumption and enhancing the mechanical properties of the cured materials [26,27]. Among the activators, $\mathrm{ZnO}$ is considered the most efficient for sulfur vulcanization and it is currently employed in the worldwide rubber industrial production. Key aspects of the curing activation are the homogeneous distribution of zinc centers in the polymer matrix, their efficient combination with the other curing agents, and their capability to form sulfurating intermediate complexes. Thus, the activation properties of $\mathrm{ZnO}$ are strongly related to its crystal structure and dispersion in the rubber.

However, a drawback of $\mathrm{ZnO}$ regards its hydrophilic character, which contrasts with the hydrophobic nature of the rubber chains. This hinders a fine distribution of $\mathrm{ZnO}$ in the elastomer during the compounding, requiring a high amount of $\mathrm{ZnO}$ to achieve homogeneous vulcanization (3-5 parts per hundred, phr). Moreover, as $\mathrm{ZnO}$ is commonly employed in the form of microsized $\mathrm{ZnO}$ crystal particles, only a reduced portion is actually able to react with the curing compounds, leading to a residual amount of unreacted oxide in rubber NCs.

Another shortcoming relies on the possible zinc release during production, service conditions, disposal, and recycling of rubber products. In the case of tires, the leaching is a consequence of the wear of tire treads. In general, zinc leaching may generate an excess of zinc concentration in the environment, potentially increasing in the future due to the widespread and expanding use of $\mathrm{ZnO}$. Many studies attempted to estimate the amount of released zinc in the United States (US) and Europe [28-32]. At the end of the nineties, the calculated amount of zinc that was derived from tire tread in the environment was of about 150 tons per year in Swedish and Great Britain [31,32].

Although zinc is a natural essential element and it is generally considered to be one of the least harmful of the heavy metals, it becomes toxic above a critical concentration, particularly for the aquatic environment, as classified by the European Chemical Agency (ECHA). The U.S. Environmental Protection Agency (EPA) has set the limit for $\mathrm{Zn}$ in drinking water at $5 \mathrm{mg} / \mathrm{L}$, while as dissolved $\mathrm{Zn}$, the maximum allowed concentration in water has been set at $120 \mu \mathrm{g} / \mathrm{L}[33,34]$.

Thus, over the last few years, the reduction of zinc content in tires and vulcanized rubber products has become an important issue [25] from the environmental point of view, in order to avoid the potential negative effects on the ecosystem and to answer the increased societal demand for low environmental impact products. Additionally, the recycling treatment of end-of-life tires would benefit from the reduction of $\mathrm{ZnO}$ amount $[35,36]$, to produce high quality regenerated rubber. In the literature, several metal oxides have been proposed as suitable alternatives for $\mathrm{ZnO}$ in rubber materials $[24,37,38]$, even if they displayed either worse activating properties or higher toxicity than $\mathrm{ZnO}$, precluding their use for $\mathrm{ZnO}$ substitution [24,37-39].

Very recently, keeping a high vulcanization efficiency, innovative zinc-based activators for rubber vulcanization process have been proposed, based on the introduction of more active and dispersed zinc centers, in order to reduce the amount of $\mathrm{ZnO}$ and the zinc leaching. The goal was to exploit the advantages derived from the higher distribution, while increasing the availability and reactivity of the activator towards the vulcanization reagents.

In this scenario, the topic of this review is the reactivity of $\mathrm{ZnO}$ as an activator for the rubber vulcanization process.

Firstly, the rubber vulcanization process will be briefly described and the catalytic role of $\mathrm{ZnO}$ will be discussed, highlighting the key points for obtaining an effective curing reaction using $\mathrm{ZnO}$ as activator. The reactive intermediates that formed in the presence of $\mathrm{ZnO}$ will be presented, in order to offer a complete overview on the $\mathrm{ZnO}$ involvement in the reaction mechanism. Subsequently, the progresses on the use of $\mathrm{ZnO}$ in rubber NCs will be reported, focusing on the improvement of vulcanization efficiency and mechanical properties of the composite materials and on the reduction of 
the $\mathrm{ZnO}$ introduced for tire compounding. The use of activators also bearing more dispersed $\mathrm{Zn}$ units will be described: nanosized $\mathrm{ZnO}$ particles; zinc complexes; zinc loaded clays; $\mathrm{ZnO}$ nanoparticles (NPs) dispersed onto different supports; and, the $\mathrm{ZnO} / \mathrm{SiO}_{2}$ double function filler, simultaneously reinforcing filler and vulcanization activator.

\section{Rubber Vulcanization}

Rubber is a widespread material for many applications in everyday life, the most significant being pneumatic tires for automobiles. Its mechanical properties (such as tensile strength and abrasion resistance [40]) are generally improved by the addition of reinforcing filler NPs [41], as carbon black, silica, and clays, typically employed to produce nanocomposites (NCs) for tires with improved abrasion resistance, wet grip, and rolling resistance [42-47]. NCs mechanical properties are further increased by the cross-linking of rubber chains through the vulcanization to form a three-dimensional network, which provides elasticity and tensile strength.

In the industrial vulcanization process, vulcanization rate and cross-linking efficiency are generally improved by using accelerators [23], activators [24,25], and co-activators. Nowadays, the most common employed accelerators are quinones [48], amines [49], benzothiazoles [50,51], sulfenamides [52], thiurames, and dithiocarbamates [53]. Examples are mercaptobenzothiazole (MBT), $\mathrm{N}$-Cyclohexyl-2-benzothiazole sulfenamide (CBS), and tetramethylthiuram disulfide (TMTD) [23]. Activators are inorganic metal derivatives (e.g., metal oxides or hydroxides) used together with co-activators (generally fatty acids or derivatives, such as stearic acid, $\mathrm{StH}$ ), able to form adducts with accelerators and to further increase their efficiency [24]. As previously observed, $\mathrm{ZnO}$ is considered to be the most efficient activator for sulfur vulcanization, where it plays a main role both in the first steps improving the kinetics of the curing reaction and at the end promoting the formation of short sulfide cross-links with the achievement of higher cross-linking densities [26].

The complexity of the interactions between the polymer and curing agents and the high number of reactions that take place simultaneously during the process, making the vulcanization mechanism not fully understood yet, despite the long history of vulcanization $[27,54]$.

The deep knowledge of the vulcanization mechanism and the development of methods for controlling rubber processing are still open challenges. In this context, several attempts have been performed to face these issues, trying to control the cross-linked structures generation in vulcanizates and the production of highly performant rubber materials.

In the past, several authors studied the curing mechanism by different approaches $[23,50,55]$, as kinetic [56-59], thermodynamic [60,61], mechanic [62], and spectroscopic [63-65]. In particular, the research that focused on the role of the different catalytic species (i.e., accelerator, activator, and co-activator) and the nature of the intermediate species, as crucial points to achieve an efficient vulcanization process. In the following, a deep insight into the different steps of vulcanization mechanism is reported, especially pointing out the role of $\mathrm{ZnO}$ as curing activator and the nature of the intermediate complexes that formed in the presence of $\mathrm{ZnO}$.

\subsection{Vulcanization Mechanism}

Sulfur vulcanization is typically applied to form chemical cross-links between the chains of unsaturated polymers, either in the backbone or in the side groups. Sulfur mainly interacts with the polymer on the allylic carbon [23]. Armstrong et al. [66] already demonstrated, in 1944, using model compound vulcanization (MCV), that sulfide cross-links are attached to the polymer chains through $\alpha$-methylene or $\alpha$-methyl groups, and that allylic isomers are therefore possible. The MCV method relies on the use of low molecular weight alkenes or other unsaturated compounds for simulating the rubber reactivity undergoing the same reaction conditions [66]. The MCV method has also been performed in most recent studies to extensively investigate the reaction mechanism [67-71] and different analytical and spectroscopic techniques have been employed to study the cross-link formation, 
such as mass spectrometry (MS), liquid chromatography coupled spectrometry (LC-MS), nuclear magnetic resonance (NMR), Raman, and Infrared (IR) spectroscopy [67,71].

Sulfur reacts with the polymer by linking together the long rubber chains by one or more sulfur atoms [72]. The length of the sulfur chemical connections directly affects the cross-linking densities of the final products, with the average number of $S$ atoms in the chains being inversely proportional to the cross-linking efficiency. The physical, chemical, and mechanical properties of a vulcanized material are correlated with the relative amount of mono-, di- or poly-sulfides connections which strongly depend on the employed vulcanization agents and procedure.

When considering the different vulcanization stages, several studies $[27,37,50,73]$ demonstrate that, in the first part of the reaction activator, the co-activator, accelerator, and the other curatives promote the formation of activated complexes that in the second part play a catalytic role in accelerating the formation of the cross-linked products. Morrison and Porter [27] proposed to divide the reaction into different consecutive steps (Figure 1a): (i) the generation of an active accelerator complex, due to the reaction between $\mathrm{ZnO}$, the co-activator $\mathrm{StH}[62,74]$ and the accelerator; (ii) the further reaction with sulfur to form an active sulfurating agent [75]; (iii) the interaction of the active sulfurating agent with the polymer to form the cross-link intermediates and successively; and, (iv) the poly-sulfide cross-linked products [26,76]. In the last steps, the cross-links between the rubber chains undergo a progressive degradation process towards shorter sulfur cross-links. In Figure 1b, the reaction steps and the intermediate structures are shown as an example in the presence of $\mathrm{ZnO}$ and $\mathrm{StH}$ as the activator and co-activator and CBS as accelerator.

a) Accelerators + Activators

Figure 1. (a) Reaction steps of rubber sulfur vulcanization [27]. Reproduced with permission from Rubber Chemistry and Technology. Copyright ${ }^{\complement}$ (1984), Rubber Division, American Chemical Society, Inc. (b) Main reactions and intermediates of the vulcanization steps (example in the presence of: $\mathrm{ZnO}$ as activator, $\mathrm{CBS}$ as accelerator and $\mathrm{StH}$ as co-activator).

The same guidelines were also suggested by other authors with little changes in the partition of the reaction steps [50,73]. Although the general agreement about the overall mechanism, several different theories are reported regarding the exact reactions that take place during the vulcanization stages and the structure of the intermediate species that are involved in this mechanism. In the following, a detailed description of the different actors and steps of vulcanization mechanism is reported.

\subsection{Activator and Co-Activator}

The first zinc complex that was involved in the vulcanization mechanism is generated by the interaction between $\mathrm{ZnO}$ and the co-activator, generally a fatty acid, such as StH. In fact, the co-activator is introduced in the process with the purpose of solubilizing $\mathrm{ZnO}$ and generating $\mathrm{Zn}^{2+}$ ions [72]. A $\mathrm{Zn}$-StH complex is supposed to form, with the structure of zinc stearate $\left(\mathrm{ZnSt}_{2}\right)$, which is able to further react with the accelerator $[23,50]$. 
The importance of the interaction between the activator and the co-activator StH to generate zinc complexes has been extensively demonstrated. McGill and Shelver [77] studied the effect of benzoic acid and StH on a 2-2'-dithiobis(benzothiazole) (MBTS) accelerated sulfur reaction of polyisoprene (PI) compounds that contain $\mathrm{ZnO}$. Their study highlighted that $\mathrm{StH}$ readily reacts with $\mathrm{ZnO}$ to form zinc salts with optimized cross-linking formation, reduced induction period, easier removal of benzothiazole groups from the accelerator (see Section 2.3), and greatly enhanced the maximum cross-linking density. Ikeda et al. [63] suggested that the first reaction between $\mathrm{ZnO}$ and $\mathrm{StH}$, together with the concentration of the $\mathrm{Zn}$-StH complex, is one of the factors that promotes the sulfur cross-linking reaction and increases the rubber cross-links. Besides, a $\mathrm{ZnO}$ excess with respect to $\mathrm{StH}$ is not beneficial in terms of mesh size, since the determinant concentration is that of $\mathrm{Zn}-\mathrm{StH}$ complex.

Recently, Ikeda et al. [78] have also explained how the composition of the complex between $\mathrm{ZnO}$ and $\mathrm{StH}$ is crucial in determining the structural network inhomogeneity of a rubber compound. By employing time-resolved zinc K-edge X-ray absorption (XAFS) and in-situ IR spectroscopies combined with Density Functional Theory (DFT) calculations, they found that the final structure of sulfur cross-linked PI was controlled by both $\mathrm{ZnO}$ and $\mathrm{StH}$ amounts. Besides, they highlighted that the intermediate complex formed between $\mathrm{ZnO}$ and $\mathrm{StH}$ is constituted by two bridging bidentate $\mathrm{StH}$ ligands coordinated to two zinc ions with a $\mathrm{Zn}: \mathrm{StH}$ molar ratio that is equal to 1:1 (Figure 2). The complex structure is $\left(\mathrm{Zn}_{2}\left(\mu-\mathrm{O}_{2} \mathrm{CC}_{17} \mathrm{H}_{35}\right)_{2}\right)^{2+}\left(\mathrm{OH}^{-}\right)_{2} \cdot \mathrm{XY}$, where $\mathrm{X}$ and $\mathrm{Y}$ are either two rubber segments, one water molecule and one rubber segment, or two water molecules as ligands.

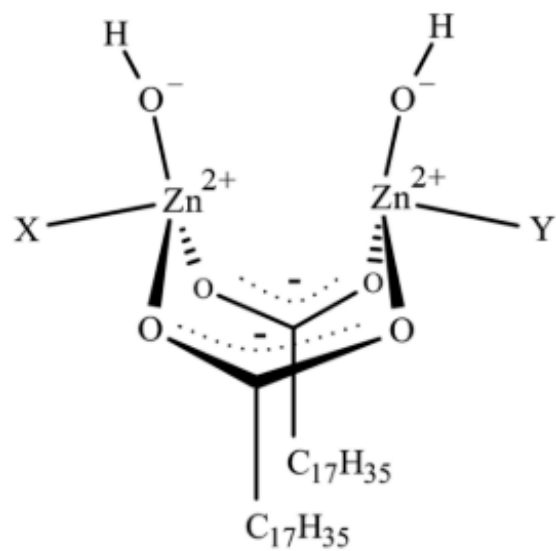

Figure 2. Proposed structure of the dinuclear type bridging bidentate zinc/stearate complex. Reprinted with permission from [78]. Copyright (2015) American Chemical Society.

This bidentate $\mathrm{Zn}-\mathrm{StH}$ complex was confirmed to be an intermediate of the successive sulfur cross-linking reactions cleavage of poly-sulfidic linkages [17]. The work has shown that the use of more sophisticated analytical methods could help in a finer research of the nature of vulcanization intermediates, elucidating more the structure of the complexes that are involved in the vulcanization mechanism in details.

\subsection{Active Accelerator Complex and Active Sulfurating Agent}

In the following steps, the $\mathrm{Zn}(\mathrm{II})$ centers are supposed to interact with the accelerator and sulfur, to give rise to the so-called active accelerator complex and active sulfurating species, respectively [72]. Figure 3a reports an example of a $\mathrm{Zn}$-accelerator complex that is generated between $\mathrm{Zn}^{2+}$ ions and MTBS proposed by Coran et al. [79]. Zinc behaves as a Lewis acid and facilitates the insertion of sulfur in the active accelerator complex favoring the S-C bond opening, and thus the formation of active sulfurating agents. Morgan et al. [80] confirmed that $\mathrm{ZnO}$ favors the opening of the sulfur rings, increasing the sulfur availability. 
(a)
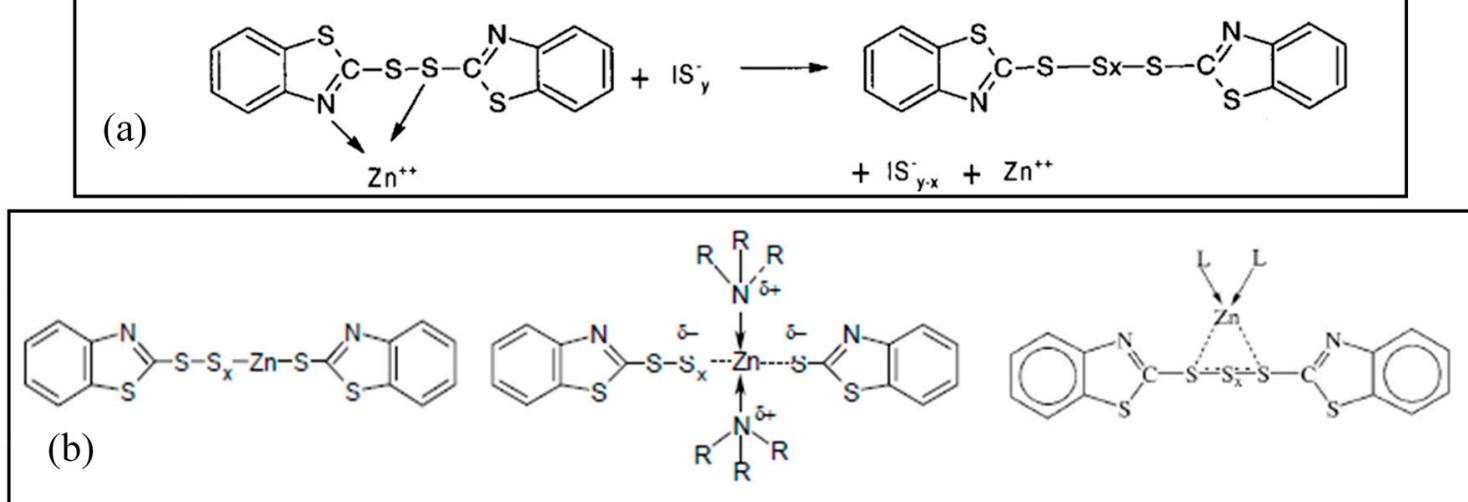

Figure 3. (a) Zinc active accelerator complex by coordination of TBBS [72] and formation of an active sulfurating complex (IS- ${ }_{\text {y }}^{-}$represents a ionized form of sulfur); (b) Structure of active sulfurating complex with zinc atom covalently bonded to the polysulfide chain; stabilization of the complex by amino ligands; structure of active sulfurating complex with a coordinative bond between zinc atom and polysulfide chain [72]. Reproduced with permission from Rubber Chemistry and Technology. Copyright $^{\complement}$ (2004), Rubber Division, American Chemical Society, Inc.

The organic pendant groups in the active sulfurating species depend on the type of the accelerator. In the case of MBTS, they are benzothiazole groups, but changing the accelerator, different pendant groups are present in the structure without changing the complex nature. Gradwell et al. [81], by using N-tert-butyl-2-benzothiazyl sulfenamide (TBBS) as accelerator, observed free amines and an active accelerator complex with a benzothiazole terminated pendent group, which is able to react with sulfur and give cross-linking reactions.

The possible structure of the active sulfurating complex has been suggested to include $\mathrm{Zn}(\mathrm{II})$ as a part of the poly-sulfidic chain, with the formation of a covalent bond with sulfur atoms (Figure 3b) [72]. In this case, the possible coordination of zinc with other ligands as amino (released from accelerators as sulphenamides) or carboxylate groups (e.g., from $\mathrm{StH}$ ) could potentially be able to increase the stability of the zinc complex (Figure 3b). However, a more probable structure has been proposed, suggesting a coordinative bond between the polysulphide chain and the $\mathrm{Zn}$ (II) center, which is stabilized by the presence of additional ligands generated in situ [50] (Figure 3b).

A significant debate is reported in the literature as concerns the occurrence of a radical or ionic vulcanization mechanism. In unaccelerated reactions, sulfur may undergo both homolytic (radical) or heterolytic (polar/ionic) reactions of $S_{8}$ ring opening (Figure 4) [23]. The same is likely to happen in accelerated reactions, but different studies were published in the attempt to clarify whether radical or ionic species are involved in the mechanism.

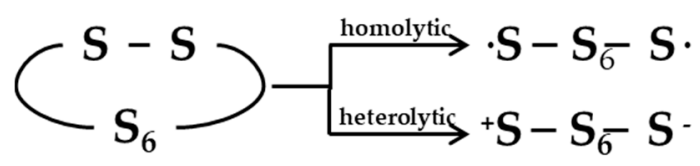

Figure 4. Homolytic and heterolytic scission of sulfur. Reprinted with permission from [23]. Copyright (1974) American Chemical Society.

Farmer et al. [82] strongly supported the presence of a radical mechanism, stating that, in the common reaction of sulfur with olefins, the opening of the sulfur ring forms a radical-terminated sulfur chain, which directly reacts with an olefin molecule in the first step of formation of cyclic mono-sulfides. Instead, a ionic mechanism was supposed by Bateman et al. [83], which suggested that the initiation step of the reaction between sulfur and olefins is the heterolytic scission of a polysulfide into polar persulfenyl intermediates and considering that homolytic breakage does not simply occur by heating sulfur or poly-sulfides at about $140^{\circ} \mathrm{C}$. However, it is still unclear whether the vulcanization reactions 
occurs via a radical or ionic pathway and it is generally assumed that the reactions probably occur via a mixture of radical and ionic mechanisms [72].

\subsection{Cross-Link Intermediates}

The active sulfurating species generally interact with the rubber at the allylic sites of the polymer unsaturation, generating the so-called cross-link precursor, whose structure consists of an accelerator terminated poly-sulfidic group that is attached to a polymer chain [72] (Figure 5a).

A delay is expected before the beginning of the cross-linking process since this latter reaction is supposed to proceed only after the previous formation of the active sulfurating species. Experimental evidences demonstrated that the addition of the accelerator, the co-activator, and $\mathrm{ZnO}$ are associated to a delay time (scorch time) required for the vulcanization to start [72]. This initial delay is fundamental from a technological point of view, because it allows for the thermal mixing and compounding of all the ingredients that are necessary for the production of the rubber-based materials before the beginning of the curing step [84,85].
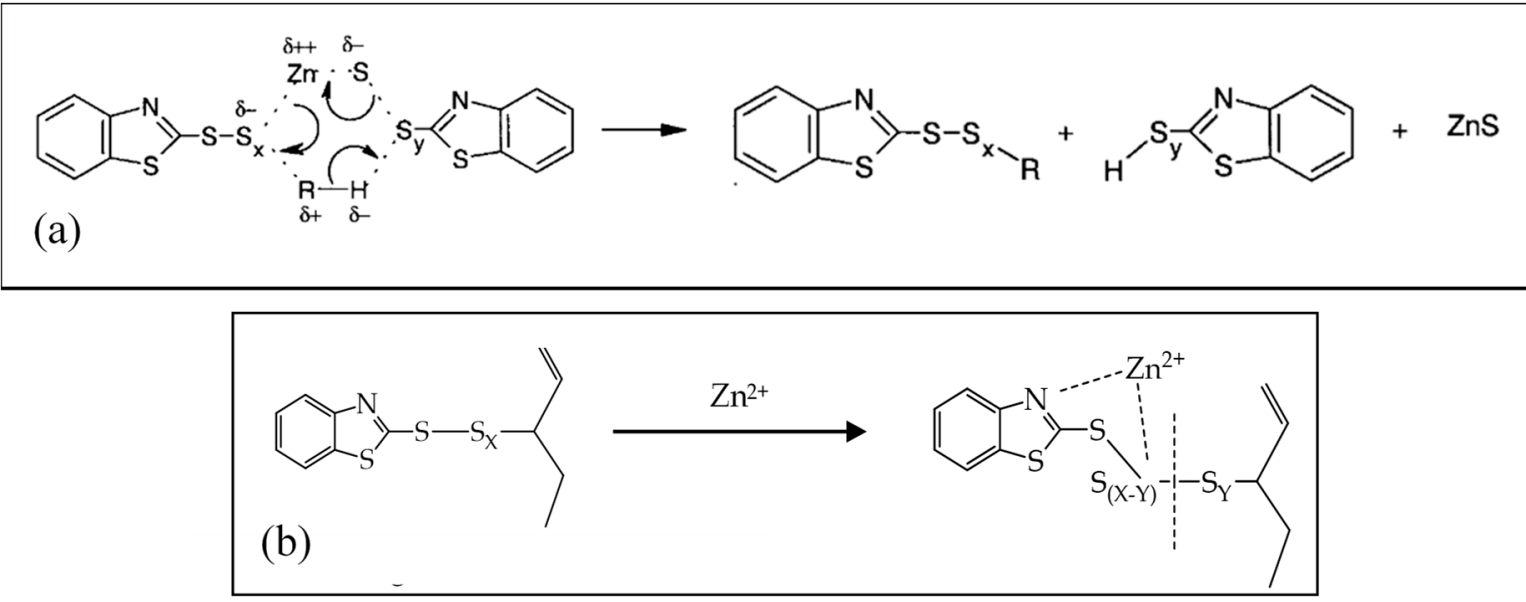

Figure 5. (a) Cross link precursor formation [72]. Reproduced with permission from Rubber Chemistry and Technology. Copyright ${ }^{\complement}$ (2004), Rubber Division, American Chemical Society, Inc. (b) Influence of Zinc on the cross-link precursor scission; reprinted from [86], Copyright (2017), with permission from Elsevier.

The role of zinc at this stage of vulcanization is crucial, even if the structure of the active sulfurating complex is still not definitely assigned (Figure 3b). In fact, zinc-based complexes must be stable enough to be formed at the first steps of the reaction, but at the same time, they must be reactive towards the rubber. In other words, the zinc-sulfur bond must be stable, but not too strong to hinder the subsequent reaction of the sulfur chain with the polymer. This factor may be discussed in first approximation in terms of bond dissociation enthalpy $\left(\Delta \mathrm{H} f_{298}\right)$. The tabulated value of $\Delta \mathrm{H} f_{298}$ for zinc-sulfur bond is $205 \mathrm{~kJ} \mathrm{~mol}^{-1}$. When comparing this value with $\Delta \mathrm{H} f_{298} \mathrm{Cu}-\mathrm{S}$, equal to $285 \mathrm{~kJ} \mathrm{~mol}^{-1}$, it can be easily deduced that copper forms stronger bonds with sulfur and the introduction of copper instead of zinc should have a detrimental effect on the vulcanization process, due to the higher stability of the intermediate species.

\subsection{Cross-Linked Products}

Finally, various mechanisms have been proposed for the conversion of the cross-link precursors into the final cross-linked products. Coran [62] proposed a mechanism that involves the reaction of the cross-link precursors with another rubber chain after the breakage of a sulfur-sulfur bond in the presence of $\mathrm{Zn}^{2+}$ centers (Figure 5b). In general, the S-S bonds tend to decompose by thermal treatment, but the presence of $\mathrm{Zn}^{2+}$ centers favors the formation of shorter sulfur bridges between the polymer 
chains. As reported for a sulphenamide-accelerated vulcanization, zinc coordinates to the nitrogen of benzothiazole group and to a sulfur atom of the sulfur chain. This coordination weakens an S-S bond farther from the accelerator moiety and closer to the rubber chain, thus decreasing the length of the sulfur chains of the cross-link intermediates (Figure 6). Later on, these intermediates link to other polymer chains. Instead, in the absence of $\mathrm{Zn}^{2+}$, the more labile S-S bond would be the one that is closest to the accelerator molecule, thus forming a longer sulfur bridge between the polymer chains.

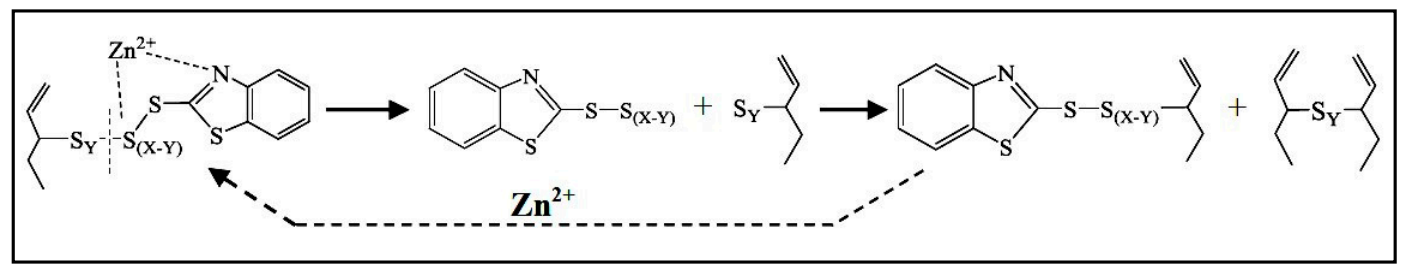

Figure 6. Mechanism of the cross-linking reaction. Reprinted from [86], Copyright (2017), with permission from Elsevier.

After the formation of the cross-linked products, this sequence can be repeated more than once on the sulfurating complex, progressively shortening the sulfur chains and giving rise to the final rubber network. Also, in this case, zinc ions are supposed to support the shortening process [86]. Zn(II) centers were also proposed [40] to break-down the already formed polysulfide cross-links.

To sum up, the $\mathrm{Zn}$ (II) centers originated from $\mathrm{ZnO}$ has proven to play a main role in all the subsequent steps of the vulcanization process, determining both the formation of more active intermediate complexes with a favorable effect on the kinetic of the reaction and affecting the nature of the cross-linked products, promoting the achievement of higher cross-linking densities.

The overview on the reaction mechanism allows for a high consciousness of the involvement of zinc species in the reaction that can lead to designing highly performant innovative $\mathrm{Zn}$-based materials to substitute $\mathrm{ZnO}$ in the activation of curing reaction, reducing the environmental issues and keeping the highly performant mechanical properties of rubber materials for the final applications.

In the literature, alternatives have been proposed to totally substitute $\mathrm{ZnO}$ in rubber materials, while using other metal oxides [24,37,38]. However, in general, the other metal oxides were demonstrated to be worse activators than $\mathrm{ZnO}$ [37]. Ducháček et al. proved that the stability of the intermediate complexes of the metal ion with the accelerator and their ability to further react with sulfur are crucial [24]. In fact, strongly coordinating cations (e.g., $\mathrm{Cu}^{2+}, \mathrm{Hg}^{2+}$ ) hinder further reaction of the complex with sulfur, while the low tendency to form complexes (e.g., $\mathrm{Mg}^{2+}, \mathrm{Ca}^{2+}$ ) makes the formation of the active sulfurating complex and the sulfur transport to the polymeric chain difficult [24]. Anyway, $\mathrm{MgO}$ shows a relatively fast kinetics in the first steps of the vulcanization, in particular when particles are nanosized [87] or in a mixture with $\mathrm{ZnO}$ [39,88], but allows for obtaining a lower cross-linking density when compared to $\mathrm{ZnO}$ [24]. Actually, $\mathrm{CdO}$ showed better activating behavior in rubber vulcanization [38], but its higher toxicity precludes its use for substituting $\mathrm{ZnO}$. Therefore, at the moment, $\mathrm{ZnO}$ still remains the most efficient activator of rubber vulcanization.

In the next paragraphs, the main pathways that were followed in the literature are described: nanosized $\mathrm{ZnO}$ particles, zinc complexes, zinc-based activators inserted in porous materials or supported on a substrate and double function filler $\mathrm{ZnO} / \mathrm{SiO}_{2}$, a material that simultaneously behaves as a reinforcing filler and curing activator.

\section{Nano vs. Micro Zinc Oxide}

The particles size reduction of the $\mathrm{ZnO}$ curing activator is a useful strategy to maintain high vulcanization efficiency and mechanical properties reducing the zinc content in rubber compounds. In fact, micro-crystalline $\mathrm{ZnO}$ is conventionally used as curing activator, but its low dispersion into the polymer matrix makes the use of high quantity of $\mathrm{ZnO}$ in rubber NCs necessary. Moreover, due to its low specific surface area, only a part of the zinc ions is accessible to react with the curing agents, leading 
to partially unreacted $\mathrm{ZnO}$, which is responsible for the high zinc leaching into the environment during the life cycle of the rubber product. Several studies have demonstrated that a high $\mathrm{ZnO}$ dispersion can be achieved by using nanosized $\mathrm{ZnO}$, which enhance the vulcanization efficiency.

Sahoo et al. [89] have studied the vulcanization rate and the mechanical properties of natural rubber (NR) and nitrile butadiene rubber (NBR) with ZnO NPs, with an average size of $50 \mathrm{~nm}$. They demonstrated that a more uniform dispersion of $\mathrm{ZnO}$ particles into the polymers (Figure 7) and a higher surface area of the oxide improve both the zinc reactivity with the curatives and the cure efficiency when compared to micro-crystalline $\mathrm{ZnO}$ activator, with about 12 to $14 \%$ enhancement of the maximum torque. Consequently, the mechanical behavior of rubber NCs also improves, due to the high cross-linking density.
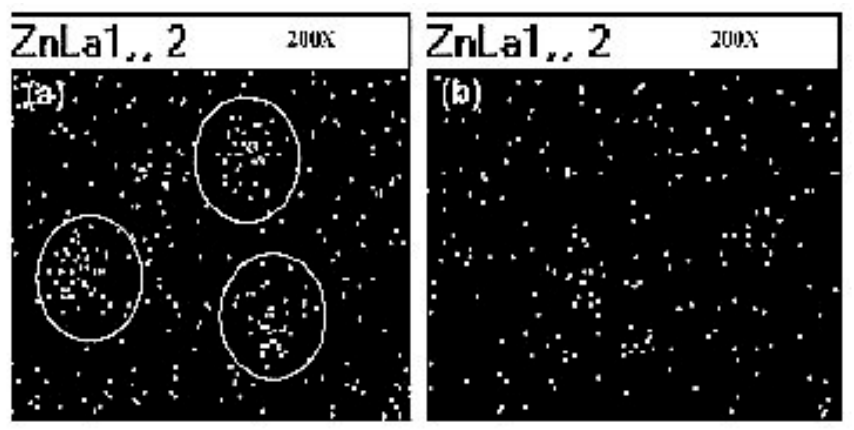

Figure 7. Scanning Electron Microscopy (SEM)/X-ray dot mapping of (a) natural rubber (NR) vulcanized with conventional rubber grade $\mathrm{ZnO}$, (b) NR vulcanized with $\mathrm{ZnO}$ nanoparticle showing dispersion of Zn(x200). Reprinted from [89], Copyright (2007), with permission from Wiley Periodicals, Inc.

Przybyszewska and Zaborski [90] studied the effect of $\mathrm{ZnO}$ particles size and morphology on the cross-linking density and on the mechanical behavior of carboxylated nitrile rubber. The authors tested ZnO NPs, having different specific surface area, particle size, and shape (i.e., spheres, whiskers, and snowflakes), and concluded that the nanosized $\mathrm{ZnO}$ allows for obtaining rubber NCs with higher cross-linking density and improved mechanical properties, if compared to those that were prepared with micro-sized $\mathrm{ZnO}$. ZnO NPs with a specific surface area of $24.43 \mathrm{~m}^{2} / \mathrm{g}$ with a three-dimensional snowflake particles morphology showed the highest activity, due to the size and shape of the agglomerates, as determined by Dynamic Light Scattering (DLS). This peculiar structure, explained as formed by wires or plates growing from a single core, was believed to be responsible for the highest tensile strength of the vulcanizates, as shown in Figure 8. However, no specific trends correlating the particles size or the particles surface areas with the cross-linking efficiency were detected.

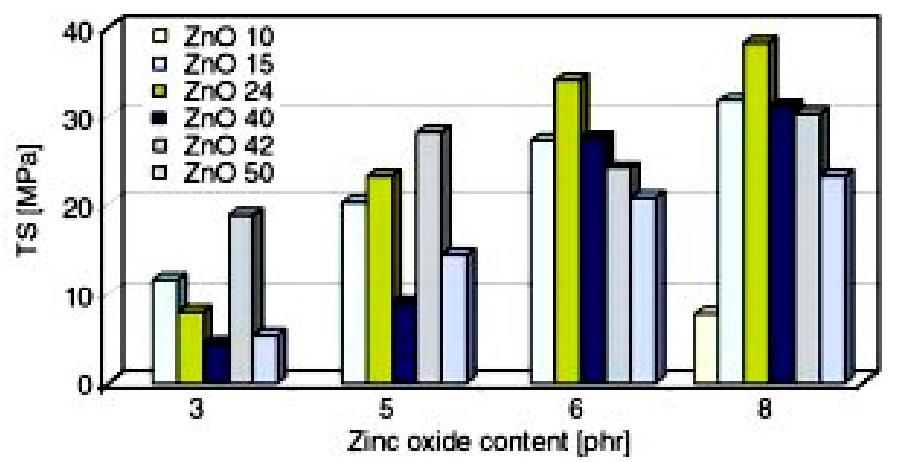

Figure 8. Tensile strength of nitrile rubber vulcanizates, containing ZnO NPs with different specific surface areas and shapes: $\mathrm{ZnO} 10,10.0 \mathrm{~m}^{2} / \mathrm{g}$-spheres and rods; $\mathrm{ZnO} 15,15.2 \mathrm{~m}^{2} / \mathrm{g}$-whiskers; $\mathrm{ZnO} 24,24.4 \mathrm{~m}^{2} / \mathrm{g}$-snowflakes; $\mathrm{ZnO} 40,40.8 \mathrm{~m}^{2} / \mathrm{g}$-spheres; $\mathrm{ZnO} 42,42.5 \mathrm{~m}^{2} / \mathrm{g}$-spheres; $\mathrm{ZnO}$ $50,50.0 \mathrm{~m}^{2} / \mathrm{g}$ - spheres. Reprinted from [90], Copyright (2009), with permission from Express Polymer Letters. 
Panampilly et al. [91] studied the effect of nanosized ZnO in NR vulcanization. ZnO NPs with an average size of $30 \mathrm{~nm}$ were synthesized from chitosan and $\mathrm{ZnCl}_{2}$. They observed a reduced optimum cure time ( $\mathrm{t} 90)$ and increased cure rate index values (CRI), while using a very small amount of nano $\mathrm{ZnO}(0.5 \mathrm{phr})$. To understand the effect of nanosized $\mathrm{ZnO}$ on both the microscopic structure and the macroscopic mechanical properties of the composites, especially in terms of the rubber-filler interactions, they estimated the bound rubber (BR), through toluene swelling measurements. BR is defined as the layer of rubber trapped on the surface of the nanofiller particles and constituted by rubber chains that were physically or chemically adsorbed to them. They found out that BR in vulcanized NR with $0.5 \mathrm{phr}$ of nano-ZnO was slightly higher than that in vulcanized NR with $5 \mathrm{phr}$ of micro $\mathrm{ZnO}$. This is related to both the higher surface area of nano- $\mathrm{ZnO}$ and its more uniform dispersion in the matrix, supporting a correlation between the higher BR and the higher rubber-filler interaction [92], due to vulcanization. Moreover, they observed that the incorporation of nano $\mathrm{ZnO}$ increases the mechanical properties when compared to micro-crystalline $\mathrm{ZnO}$.

Roy et al. [93] studied the effect of nano $\mathrm{ZnO}$ that was synthetized by sol-gel method, finding that the addition of $0.5 \mathrm{phr}$ of nano $\mathrm{ZnO}$ in NR caused the decrease of the optimum cure time and the enhancement of the CRI index as compared to NC enclosing $5 \mathrm{phr}$ of conventional $\mathrm{ZnO}$. Moreover, an improvement of the mechanical properties of vulcanized NR was observed, because of the higher surface area and better dispersion and distribution of the cure activator within the rubber. From Thermo Gravimetric Analysis (TGA), they demonstrated that a better thermal stability of rubber composites, including nano $\mathrm{ZnO}$, depends on the decrease of the thermal motion of polymer chain within the network structure.

Cui et al. [94] have studied the effect of ZnO NPs with specific crystal facets being exposed on the vulcanization efficiency. Two different structures of $\mathrm{ZnO}$ were analyzed, a table-like (T-ZnO) and rod-like $\mathrm{ZnO}(\mathrm{R}-\mathrm{ZnO})$ having the approximately same particles size and specific surface area. The results revealed that styrene-butadiene rubber (SBR) composites that were prepared with $\mathrm{R}-\mathrm{ZnO}$ presents higher density of cross-linking and better mechanical properties than those from T-ZnO. Besides, a faster curing rate was evidenced, which indicated that $\mathrm{R}-\mathrm{ZnO}$ with more exposed (100) crystal face has better vulcanization activity. X-Ray Diffraction (XRD) and X-Ray Photoluminescence Spectroscopy (XPS) measurements showed that a higher quantity of $\mathrm{Zn}$ is exposed on the surface of crystal T-ZnO, but less free $\mathrm{Zn}^{2+}$ ions are formed in the T-SBR. In fact, DFT calculation assessed that $\mathrm{Zn}^{2+}$ binding energy of $\mathrm{ZnO}$ surface were $23.13 \mathrm{eV}, 25.30 \mathrm{eV}, 22.31 \mathrm{eV}, 23.4 \mathrm{eV}$ for crystallographic plane (001), (001), (100) $1,(100)_{2}$, respectively, and that the lower binding energy was beneficial for the release of $\mathrm{Zn}^{2+}$.

In conclusion, different approaches concerning the reduction of the dimension of the activator have been reported in the literature. Reducing the size of zinc oxide particles has proven to be an effective strategy to enhance the vulcanization efficiency. In fact, $\mathrm{ZnO}$ nanometric dimensions favor a better dispersion and distribution of the activator in the polymer matrix, due to the higher surface area of the NPs, promoting the interaction of zinc centers with curing agents and rubber chains.

However, micro-sized $\mathrm{ZnO}$ is still the most widely used activator in the rubber industry, mainly because the development of large-scale synthetic procedures of $\mathrm{ZnO} N$ Ps requires much effort. Many different methods (e.g., solvothermal, hot-injection, miniemulsion) are known to obtain ZnO NPs, but $\mathrm{ZnO}$ NPs have the tendency to crystallize in hexagonal phase, growing along selective crystal planes and giving anisotropic crystals [95]. Although the structural and morphological control of $\mathrm{ZnO}$ NPs in lab-scale protocols is high, these methods are not cost-effective or only a relatively small quantity of particles per batch can be obtained.

\section{Zinc(II) Complexes}

When considering that the attempts to use other environmentally friendly metal oxides demonstrated the higher and unique activation efficiency of zinc ions, significant endeavors for 
improving the vulcanization efficiency and reducing the $\mathrm{ZnO}$ consumption in rubber NCs have been focused on the use of $Z n$-based compounds.

Several $\mathrm{Zn}(\mathrm{II})$ complexes have been selected as the possible candidates for $\mathrm{ZnO}$ substitution. The choice of the suitable ligands for the zinc complexes was based on the role of $\mathrm{Zn}^{2+}$ complex that was generated from $\mathrm{ZnO}$ interaction with $\mathrm{StH}$, able to interact with the curative agents to generate the active sulfurating complexes (Section 2.2).

Several authors tried to apply zinc complexes instead of $\mathrm{ZnO}$ and $\mathrm{StH}$ as activators. This strategy should increase the number of zinc ions that are available as activator, reducing the amount of $\mathrm{ZnO}$ currently employed in rubber NCs.

Heideman et al. $[96,97]$ tested the reactivity of four different zinc complexes on the cure and physical properties of two rubbers, Ethylene-Propylene Diene Monomer (EPDM) and s-SBR. Zinc stearate, which is supposed to be an intermediate species of curing mechanism [50], 2-zinc ethylhexanoate, borate and m-glycerolate commonly used as flame-retardant, cosmetical, and pharmaceutics, were tested. Interestingly, the cross-linking density measured by swelling was considerably lower with zinc stearate, when compared to the compound containing $\mathrm{ZnO}$ and $\mathrm{StH}$ as separate components, which indicated an unexpected lower activity towards the vulcanization of both EPDM and s-SBR (Figure 9a).
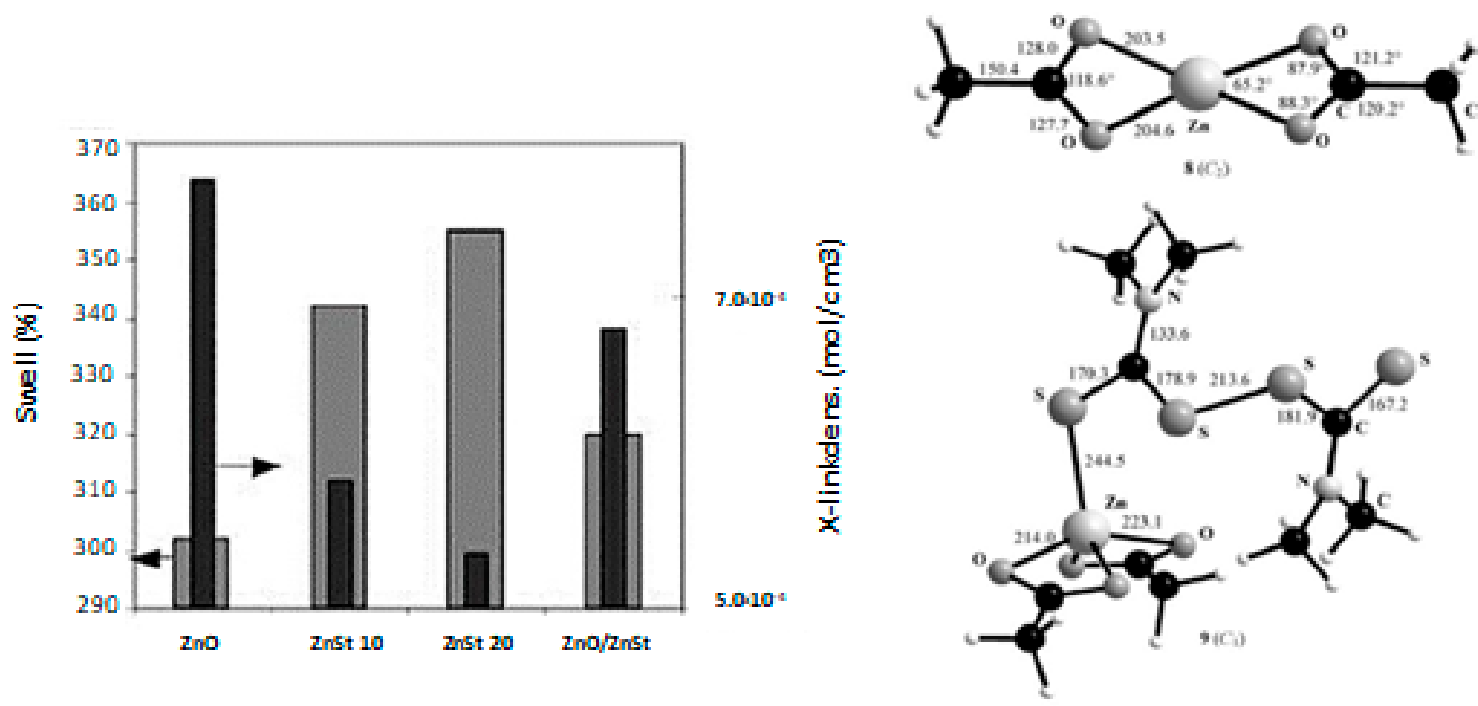

Figure 9. (a) Swelling and cross-linking density of s-SBR compounds with zinc stearate (moving from the left to the right: zinc oxide $3 \mathrm{phr}$, zinc stearate $\left(\mathrm{ZnSt}_{2}\right) 10$ and $20 \mathrm{phr}$ respectively and zinc oxide/zinc stearate 0.5/6.1 phr). Reprinted from [97], Copyright (2006), with permission from Wiley-VCH, Inc. (b) Structure of zinc acetate complex and of $\mathrm{Zn}(\mathrm{OOCMe})_{2}$ (TMTD) calculated; Reprinted from [98], Copyright (2008), with permission from Wiley-VCH, Inc.

Theoretical studies regarding the interaction of zinc complexes (especially of zinc stearate) with the other curing agents were carried out in order to investigate their reactivity and the reaction kinetic for the formation of the vulcanization intermediates. Ab initio studies and DFT calculations that were performed on the interaction between TMTD with a number of zinc(II) species, such as $\mathrm{Zn}(\mathrm{OOCMe})_{2}$ [98] (Figure 9b), highlighted that the zinc carboxylate complexes are less efficient activators when compared to $\mathrm{ZnO}$, mainly because of the fourfold coordination of the zinc atoms in conjunction with strong residual $\mathrm{Zn}-\mathrm{O}$ bonds. On the contrary, $\mathrm{ZnO}$ participates in the formation of zinc adducts with the accelerator TMTD through its dissolution in rubber driven by $\mathrm{StH}$, activating the accelerator and at the same time dissolving the progressive incoming ligands and forming strong $\mathrm{Zn}-\mathrm{S}$ bonds. These results agreed with the observations of Heideman et al. [96] regarding zinc stearate, pointing out the main role that is played by the coordination of zinc. Heideman et al. [96] also showed that other zinc carboxylate complexes (as zinc m-glycerolate) surprisingly behave differently than zinc stearate, promoting both the increase of the cross-linking density and the improvement of the 
mechanical properties of rubber compounds, which is in contrast with the theoretical study. This suggests that further studies are mandatory to understand whether the coordination of $\mathrm{Zn}^{2+}$ ions can be suitably modulated by tuning the counter-ions in zinc complexes, and consequently the reactivity and availability of $\mathrm{Zn}^{2+}$.

Przybyszewska et al. [99] reported the different activities of several zinc chelates as curing activators for NBR while using MBT as accelerator: 1,3-diketones (i.e., 1,3-diphenylpropane-1,3-dione, BM-Zn) as well as zinc acetylacetonate (AAC-Zn). The higher stability of zinc complexes, determined by their heat of formation, was related to the lower availability of zinc ions and the lower tendency to form zinc-accelerator complexes during the reaction. In fact, AAC-Zn demonstrated a lower efficiency in the vulcanization when compared to BM-Zn complex, which was probably due to the higher AAC-Zn stability. No detrimental effects on the cross-linking rate or physical properties of the vulcanized products were registered, even though a reduction of the cross-linking densities and efficiency of cross-linking process were shown.

Zinc dithiocarbamates were tested as combined activators and accelerators of vulcanization reaction by Alam et al. [100], in the presence of thiazole-based accelerators. These complexes showed very effective synergistic activity with other accelerators, such as MBTS, MBT, and CBS, with increasing torque, tensile strength, and elongation at break. Nevertheless, rubber was vulcanized by zinc complexes in the presence of the typical curing agents of a sulfur-based vulcanization process, including micro-crystalline $\mathrm{ZnO}(5 \mathrm{phr})$. Thus, the improved mechanical properties were assigned to a greater enhancement of the curing reaction due to the contribution of these zinc dithiocarbamates complexes, but together with the conventional activator $\mathrm{ZnO}$ and without reducing zinc content in rubber compounds.

Other attempts have been reported by international companies. Cray Valley USA in a Technical Meeting of the ACS Rubber Division [101], claimed that reduced zinc loading in rubber NCs could be achieved by a zinc monomethacrylate complex (ZMMA). This complex was recognized to improve the activating efficiency, increasing both the cross-linking densities and mechanical properties.

Recently, the increasing concerns towards green alternatives have pushed the scientific research to find more eco-friendly and sustainable candidates for substituting $\mathrm{ZnO}$ and $\mathrm{StH}$ in rubber compounds. In this perspective, Moresco et al. have examined the performances of a vegetable oil as vulcanization activator and lubricant for the preparation of low zinc content NR tire tread [102]. Thermal and chemical characterizations suggested that this material has the typical structure of an aromatic zinc carboxylate. The mechanical properties of the correspondent rubber NCs demonstrate that the naturally derived zinc complex could be used instead of $\mathrm{ZnO}$, without affecting the physico-mechanical behavior of the compounds, reducing the zinc content by $75 \%$ compared to the standard formulation that contains $5 \mathrm{phr}$ of $\mathrm{ZnO}$. Another great advantage was the double function of the vegetable oil, being able to act both as an activator and as a lubricant from a vegetable source.

Zanchet et al. developed a green additive, which is composed of an activator derived from sugar cane, as a residue of the ethanol production [103]. From TGA the composition of this material resulted of water, zinc carboxylate, $\mathrm{StH}$, and lignin, with a zinc content of $25.6 \%$. This green additive was able to promote the formation of a higher number of S-S bonds in rubber compounding, even if with a reduction of the resistance to weathering conditions, in comparison with a reference material vulcanized with $\mathrm{ZnO}$. Besides, the lower cross-linking densities were ascribed to the possible interaction of lignin with the accelerators during the reaction, due to its acidity and to its properties of radical scavenging that are connected to the hindered phenol moiety included in the structure. Later on, the authors tested the same material after a surface modification treatment, aiming at an improvement of the dispersion in NR composites [104] and obtaining higher thermal stability and reinforcement effect due to a better dispersion of the additive in the matrix, thanks to the surface functionalization.

To sum up, the substitution of $\mathrm{ZnO}$ and $\mathrm{StH}$ with new zinc complexes demonstrated to be a promising pathway, even if the stability and the structure of the complex is a key point for determining its reactivity as activator. High stability and strong coordinative bonds are fundamental for using a 
zinc complex as an activator of a thermal reaction, but at the same time could be detrimental regarding its activity towards the curative agents. Thus, more studies should be performed in order to investigate the correlations between the structure of the zinc complexes and their reactivity in the vulcanization process, paving the way towards the design of more reactive zinc-based activators by finely tuning the chemical neighborhood of zinc ions.

\section{Homogeneous Distribution of Curing Agents}

One of the main problems that is related to the addition of $\mathrm{ZnO}$ in rubber NCs is its low distribution degree, due to the hydrophobic character of the polymer chains, which favors the aggregation of the hydrophilic $\mathrm{ZnO}$ particles in the rubber matrix. This implies the addition of large amounts of $\mathrm{ZnO}$ to afford its distribution into the whole matrix and to avoid the formation of rubber islands without $\mathrm{ZnO}$, which would affect the local efficiency of the vulcanization process [105].

In this paragraph, attempts to enhance the vulcanization efficiency and homogeneity through the improvement of the distribution of the curing agents are reported. Generally, two roads are followed: (i) the improvement of the distribution of sulfur and accelerator curatives in the rubber matrix to make them more available to react with $\mathrm{ZnO}$ activator and (ii) a better distribution of $\mathrm{ZnO}$ or zinc-based activator by supporting them on a substrate or by inserting them in porous materials (see Section 5.1).

The distribution of either sulfur or the accelerator in the rubber compound has been extensively investigated. Chen et al. [106] developed $\mathrm{SiO}_{2} \mathrm{NPs}$ that were functionalized with aliphatic ether polysulfide (silica-s-VA7), which can behave simultaneously as cross-linking centers for the rubber chains and as interfacial compatibilizer of $\mathrm{SiO}_{2}$ particles (Figure 10). They claim that silica functionalization occurs through hydrogen bonding between the surface silanol groups and the ether group of VA7. Scanning Electron Microscopy (SEM) analysis evidenced improved filler-rubber interactions, thanks to the covalent linkages between the elastomer and the nanofiller, which were responsible for lower energy dissipation.

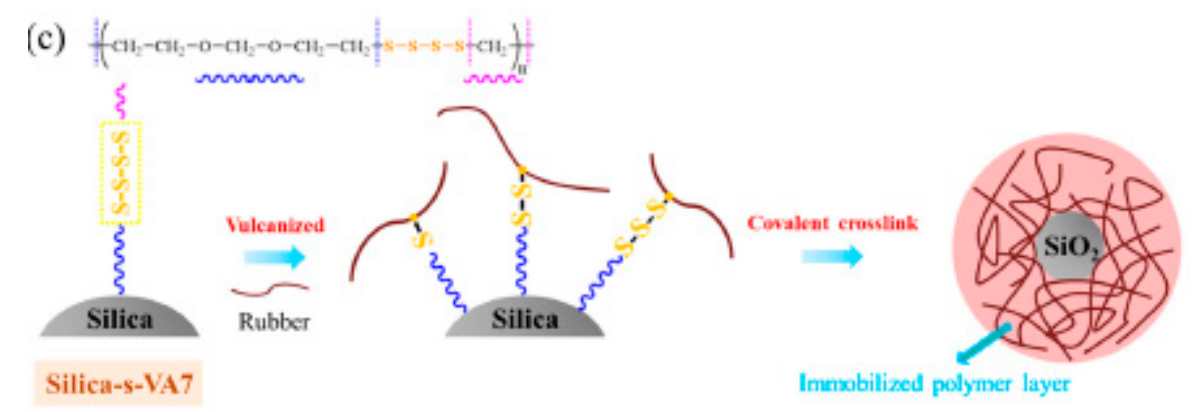

Figure 10. Interface reaction in SBR/silica-s-VA7 composites during the vulcanization process. Reproduced from [106].

Sulfur monochloride was also supported onto the $\mathrm{SiO}_{2}$ surface [107], which evidenced that the formation of interparticle domains was responsible for a significant enhancement of the mechanical properties of NR NCs.

Accelerator molecules, such as diphenyl guanidine (DPG) [108], CBS [109], and ethylenthiourea (ETU) [110], were covalently supported onto silica and studied in the reinforcement of sSBR/BR composites. The homogeneous distribution of the curing agents in the polymer matrix increased the mechanical properties, mainly for a more uniform formation of cross-links.

\subsection{Zinc-Based Activators Inserted in Porous Materials or Supported on a Substrate}

Focusing on the distribution of $\mathrm{ZnO}$ or zinc-based activators, two main approaches are mainly present in the literature: (i) zinc ions that are distributed as cations inside porous materials (e.g., clays) and (ii) $\mathrm{ZnO} \mathrm{NPs} \mathrm{distributed} \mathrm{through} \mathrm{the} \mathrm{addition} \mathrm{of} \mathrm{suitable} \mathrm{dispersing} \mathrm{agents} \mathrm{or} \mathrm{by} \mathrm{anchoring} \mathrm{them}$ onto the surface of different supports (e.g., silica, graphene). 
As regarding the first approach, zinc loaded clays were first developed by Heideman et al. [111,112], assuming that an increase of the availability of zinc ions could considerably reduce the $\mathrm{ZnO}$ amount in rubber compounds. $\mathrm{Zn}^{2+}$ ions were loaded onto a montmorillonite clay $\left(\mathrm{Al}_{2} \mathrm{O}_{3} \cdot 4 \mathrm{SiO}_{2} \cdot \times \mathrm{H}_{2} \mathrm{O}\right)$, a 2:1 layered silicate (Figure 11), by the substitution of the exchangeable cations of the clay with zinc ions. First, an acid treatment allows for obtaining hydrogen-rich clay, whose successive displacement obtains the zinc ion-saturated clay (Zn-Clay). The use of Zn-Clay as activator ( $5 \mathrm{phr}$ of $\mathrm{Zn}$-Clay, with a Zn loading of $\sim 5 \%$ ) evidenced that the vulcanization process is as efficient as in the presence of $3 \mathrm{phr}$ of $\mathrm{ZnO}$. MCV studies also demonstrated that $\mathrm{Zn}$-Clay fastens the cross-link precursor formation, without negatively affecting the mechanical properties of the cured material.

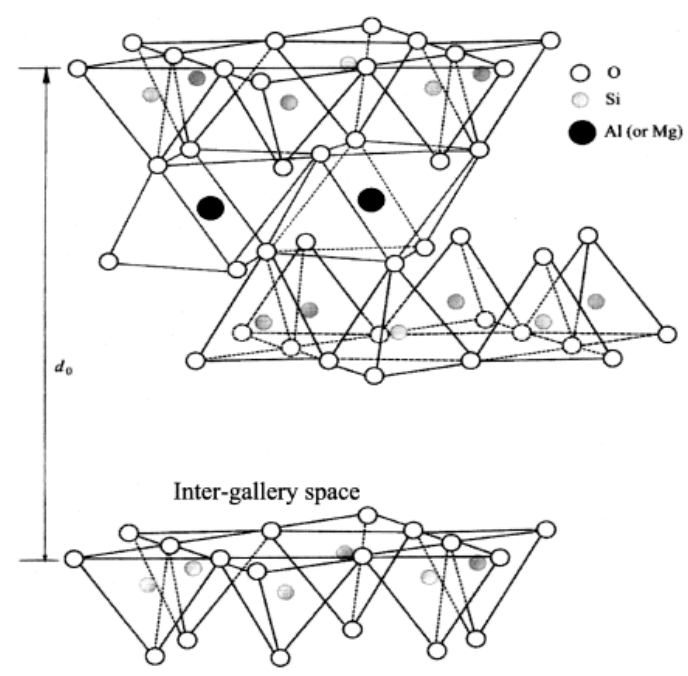

Figure 11. Crystalline structure of a 2:1 layered silicate. Reproduced from [111].

Another study reports the development of zinc stearate-modified layered double hydroxides (LDH) and their use for NR compounds formulation to eliminate $\mathrm{ZnO}$ and StH [113]. The material was demonstrated to behave both as activator of vulcanization, favoring the release of $\mathrm{Zn}^{2+}$ ions and as reinforcing filler, even if to a marginal extent.

A few options are reported regarding the use of suitable dispersing agents in order to develop highly distributed $\mathrm{ZnO}$ NPs systems. Higher $\mathrm{ZnO}$ distribution were achieved by surface functionalization with silane coupling agents of pre-synthesized ZnO NPs [114], whose nanodimensions could favor curing efficiency. Gujel et al. demonstrated that dispersing functionalized ZnO NPs in a commercial formulation containing $\mathrm{CaCO}_{3}$, a higher distribution of $\mathrm{ZnO}$ in rubber compounds was achieved [115], allowing for a possible increase of the exposed surface area when compared to micro-crystalline $\mathrm{ZnO}$ that makes them more reactive. Most importantly, the authors suggested that manufacture product release might impact the cytotoxic effect of the final material, because a modification of $\mathrm{ZnO}$ reactivity could promote a different reaction mechanism, involving different intermediate species. This approach is relatively simple and effective to favor the $\mathrm{ZnO}$ distribution, but it presents two drawbacks that were related to the insertion of the dispersing agent in the composite, which can affect its properties, and to the functionalization of $\mathrm{ZnO}$, which may affect their surface reactivity towards the curatives.

The development of anchored $\mathrm{ZnO}$ NPs on different supports was recognized as a suitable approach to strongly enhance the $\mathrm{ZnO}$ distribution in the polymeric matrix supporting the catalytic species on other additives as silica or graphene through covalent bonds or physical interactions. The main advantage of this method relies on the combined effect of the increased surface due to nanosized $\mathrm{ZnO}$ and the enhanced distribution of $\mathrm{ZnO}$, which cooperate in increasing the zinc ions availability and reactivity towards the other curing agents. The effects on the catalytic properties of supported species, including noble metals or metal oxides, is well known [116,117], especially for recyclable photocatalysts $[118,119]$ or catalytic reactions as dehydrogenation [120]. 
Recently, a zinc-based activator constituted by ZnO NPs supported on silica was first introduced as rubber curing activator [121]. ZnO NPs anchored on the surface of silica particles (Figure 12) were synthesized through a sol-gel procedure, in which hydrolysis and condensation of a zinc precursor led to the in-situ formation of ZnO NPs, covalently bonded to the silica surface, as demonstrated by the detection of $\mathrm{Si}-\mathrm{O}-\mathrm{Zn}$ bonds [121]. $\mathrm{ZnO} / \mathrm{SiO}_{2}$ particles were defined as double function filler, because they are composed of silica particles that simultaneously behave as a reinforcing filler and as support for $\mathrm{ZnO} N \mathrm{Ns}$, which are able to activate the vulcanization reaction.

a)

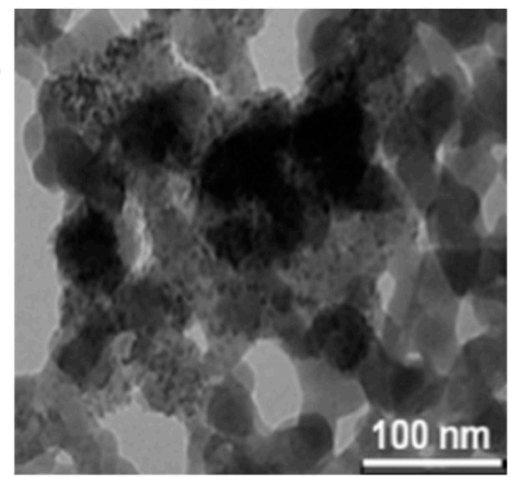

b)

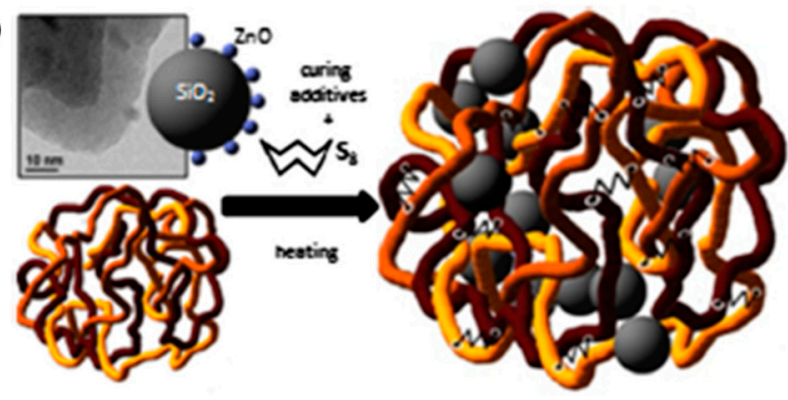

Figure 12. (a) Transmission Electron Microscopy (TEM) image of ZnO NPs anchored onto the surface of $\mathrm{SiO}_{2} \mathrm{NPs}\left(\mathrm{ZnO} / \mathrm{SiO}_{2}\right)$; (b) Graphical representation of $\mathrm{ZnO} / \mathrm{SiO}_{2} \mathrm{NPs}$ and their incorporation into PI matrix after vulcanization. Reprinted from [121], Copyright (2015), with permission from Elsevier.

$\mathrm{ZnO} / \mathrm{SiO}_{2}$ shows high catalytic properties for the activation of the vulcanization reaction of PI, leading to higher cross-linked rubber compounds with improved mechanical properties compared to the reference samples in which micro- $\mathrm{ZnO}$ was employed as activator. Besides, by deeply investigating the reaction mechanism by $\mathrm{MCV}$, it was concluded that the different $\mathrm{ZnO}$ morphology and enhanced distribution were able to improve both the kinetic of the reaction and the nature of the cross-linked products, leading to shorter sulfur-sulfur bridges between polymer chains, responsible for the higher cross-linking density [86]. A different pathway of interaction between $\mathrm{ZnO}$ NPs and StH was also suggested to occur, based on recent evidences proposed by Ikeda et al. [78], in which the formation of a new zinc-stearate complex was involved (Figure 2). Thus, both the distribution and the morphology have demonstrated to profoundly affect both the mechanism and the kinetics of vulcanization, allowing a reduction of the zinc loading of at least 30\% than that traditionally employed.

Since the proposal of $\mathrm{ZnO} / \mathrm{SiO}_{2}$ as double function filler activator, other similar approaches have been suggested in the literature aiming at improving morphology and distribution of $\mathrm{ZnO}$. In fact, $\mathrm{ZnO}$ NPs bonded to $\mathrm{SiO}_{2}$ filler were prepared according to the same procedure proposed by Susanna et al. [121] and tested for the preparation of cold vulcanizing adhesives [122]. More recently, nanosized zinc hydroxide with plate-like structures were synthesized by sol-gel precipitation onto precipitated silica, showing high efficiency as curing activator for NR with high CRI values [123].

Other examples involve different substrates. Graphene decorated with ZnO NPs, were developed to improve either static-dynamic mechanical properties and gas barrier properties of NR NCs [124]. Naturally available supports as cellulosic fibers were surface modified through a wet mixing method to incorporate $\mathrm{ZnO}$ particles with rod like structures on the fibers surface (Figure 13), showing high distribution of $\mathrm{ZnO}$ particles and a filler-NR bond at the interface stronger than that with bare cellulosic fiber, as well as higher tensile strength and stiffness [125].

Thus, the higher distribution of zinc oxide or zinc ions in the rubber matrix has been shown to play a main role in the improvement of the vulcanization efficiency and the achievement of highly performant rubber-based materials. Several promising candidates for the substitution of bare $\mathrm{ZnO}$ were prepared by exploiting the presence of different supports to better distribute either ZnO NPs or zinc centers, which makes them more reactive towards the curatives. This latter approach also 
demonstrated that further studies in this field could design and develop even more efficient zinc-based activators, by further increasing the availability and the reactivity of the single $\mathrm{Zn}^{2+}$ ions through supporting reactive $\mathrm{Zn}$-based compounds on suitable substrates.

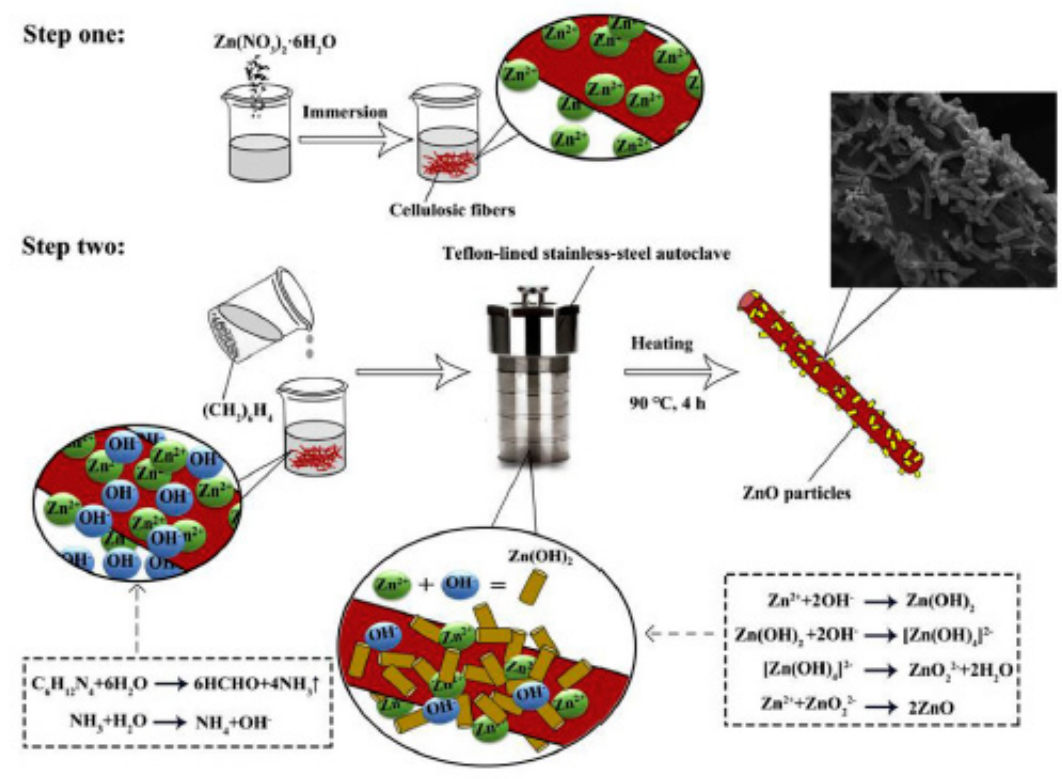

Figure 13. Schematic of in-situ synthesis of $\mathrm{ZnO}$ particles on cellulosic fibers surface. Reprinted from [125], Copyright (2019), with permission from Elsevier.

\section{Conclusions}

In the present review, the catalytic role of $\mathrm{ZnO}$ in the vulcanization process of rubber-based materials has been discussed and the key points of the curing mechanism using $\mathrm{ZnO}$ as an activator are highlighted.

A crucial role was recognized to $\mathrm{Zn}$ (II) centers that originated from $\mathrm{ZnO}$ in all of the subsequent steps of the vulcanization process, determining both the formation of more active intermediate complexes, with a favorable effect on the kinetic of the reaction, and affecting the nature of the vulcanized products, promoting the achievement of high cross-link density.

Innovative $\mathrm{Zn}$-based activators for rubber vulcanization have been proposed in the literature in order to reduce the amount of $\mathrm{ZnO}$ used in the process keeping a high vulcanization efficiency since the high content of $\mathrm{ZnO}$ in rubber composites and the possible release of zinc in the environment during the life cycle of the rubber products are becoming an important environmental issue.

The review gives an overview of the main pathways for designing highly performant innovative $\mathrm{Zn}$-based materials to substitute conventional $\mathrm{ZnO}$ in curing activation, based on the introduction of more active and dispersed zinc centers with high availability and reactivity towards the vulcanization reagents:

- $\quad$ tailored nanosized $\mathrm{ZnO}$ particles to achieve a better distribution and availability of the activator in rubber, thanks to their high surface area;

- $\quad \mathrm{Zn}(\mathrm{II})$ complexes to favor the interaction of already formed zinc centers with the curing agents, and thus to generate the sulfurating intermediate complexes active into vulcanization process;

- $\quad$ zinc-based activators constituted by $\mathrm{Zn}^{2+}$ ions inserted in porous materials (e.g., clays) or $\mathrm{ZnO}$ NPs distributed through the addition of dispersing agents, to improve the availability of the zinc centers to react with the curatives; and,

- $\quad$ supported $\mathrm{Zn}$-based activators, consisting of $\mathrm{ZnO}$ NPs onto the surface of different supports (e.g., silica, graphene) and in particular $\mathrm{ZnO} / \mathrm{SiO}_{2}$ double function filler, simultaneously behaving as rubber reinforcing filler and curing activator. 
Many of the proposed Zn-based activators demonstrated to be promising pathways for substituting $\mathrm{ZnO}$ in vulcanization. The higher distribution of $\mathrm{ZnO}$ or $\mathrm{Zn}$ ions in the rubber matrix has shown to play the main role in the improvement of the vulcanization efficiency and the achievement of highly performant rubber-based materials. Nevertheless, their possible application in an industrial process is still far away, due to the requirement of scaling-up the production of the novel activators and of a deeper knowledge of the structure-reactivity correlation of the Zn-based activator in the vulcanization process.

Funding: The APC was funded by European Institute of Innovation and Technology (EIT), a body of the European Union, under the Horizon 2020, the EU Framework Programme for Research and Innovation.

Acknowledgments: P.M. thanks CORIMAV (Consortium for the Research of Advanced Materials between Pirelli and Milano Bicocca University) for its support within the Doctoral Program.

Conflicts of Interest: The authors declare no conflict of interest.

\section{References}

1. Ma, H.; Williams, P.L.; Diamond, S.A. Ecotoxicity of manufactured $\mathrm{ZnO}$ nanoparticles-A review. Environ. Pollut. 2013, 172, 76-85. [CrossRef] [PubMed]

2. Vaseem, M.; Umar, A.; Hahn, Y. ZnO Nanoparticles: Growth, Properties, and Applications. J. Mater. Chem. 1988, 22, 6526-6535.

3. Carotta, M.C.; Cervi, A.; Natale, V.; Gherardi, S.; Giberti, A.; Guidi, V.; Puzzovio, D.; Vendemiati, B.; Martinelli, G.; Sacerdoti, M.; et al. ZnO gas sensors: A comparison between nanoparticles and nanotetrapods-based thick films. Sens. Actuators B Chem. 2009, 137, 164-169. [CrossRef]

4. Zhu, L.; Zeng, W. Sensors and Actuators a: Physical Room-temperature gas sensing of ZnO-based gas sensor: A review. Sens. Actuators A Phys. 2017, 267, 242-261. [CrossRef]

5. Haarindraprasad, R.; Hashim, U.; Gopinath, S.C.B.; Kashif, M.; Veeradasan, P.; Balakrishnan, S.R.; Foo, K.L.; Poopalan, P. Low Temperature Annealed Zinc Oxide Nanostructured Thin Film-Based Transducers: Characterization for Sensing Applications. PLoS ONE 2015, 10, e0132755. [CrossRef] [PubMed]

6. Klemm, D.; Heublein, B.; Fink, H.P.; Bohn, A. Cellulose: Fascinating biopolymer and sustainable raw material. Angew. Chem. Int. Ed. 2005, 44, 3358-3393. [CrossRef] [PubMed]

7. French, S.A.; Sokol, A.A.; Bromley, S.T.; Catlow, C.R.A.; Rogers, S.C.; King, F.; Sherwood, P. From $\mathrm{CO}_{2}$ to methanol by hybrid QM/MM embedding. Angew. Chem. Int. Ed. 2001, 40, 4437-4440. [CrossRef]

8. Natta, G. Synthesis of methanol. Catalysis 1955, 3, 349-411.

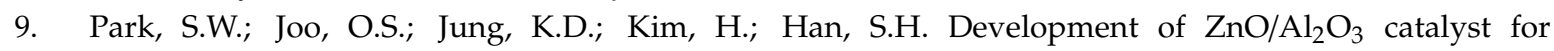
reverse-water-gas-shift reaction of CAMERE (carbon dioxide hydrogenation to form methanol via a reverse-water-gas-shift reaction) process. Appl. Catal. A Gen. 2001, 211, 81-90. [CrossRef]

10. Shido, T.; Yamaguchi, A.; Asakura, K.; Iwasawa, Y. Surface catalytic reactions assisted by gas phase molecules: Activation of reaction intermediates. J. Mol. Catal. A Chem. 2000, 163, 67-77. [CrossRef]

11. Shido, T.; Iwasawa, Y. Reactant-promoted reaction mechanism for water-gas shift reaction on $\mathrm{ZnO}$, as the genesis of surface catalysis. J. Catal. 1991, 129, 343-355. [CrossRef]

12. Ueno, A.; Yamamoto, T.; Onishi, T.; Tamaru, K. The Behaviour of Chemisorbed Species under the Reaction Conditions and the Mechanism of the Water-gas Shift Reaction on $\mathrm{ZnO}$ and MgO. Bull. Chem. Soc. Jpn. 1969, 42, 3040. [CrossRef]

13. Shishido, T.; Yamamoto, Y.; Morioka, H.; Takaki, K.; Takehira, $\mathrm{K}$. Active $\mathrm{Cu} / \mathrm{ZnO}$ and $\mathrm{Cu} / \mathrm{ZnO} / \mathrm{Al} 2 \mathrm{O} 3$ catalysts prepared by homogeneous precipitation method in steam reforming of methanol. Appl. Catal. A Gen. 2004, 263, 249-253. [CrossRef]

14. Chin, Y.; Dagle, R.; Hu, J.; Dohnalkova, A.C.; Wang, Y. Steam reforming of methanol over highly active $\mathrm{Pd} / \mathrm{ZnO}$ catalyst. Catal. Today 2002, 77, 79-88. [CrossRef]

15. Hoffmann, M.R.; Martin, S.T.; Choi, W.; Bahnemann, D.W. Environmental Applications of Semiconductor Photocatalysis. Chem. Rev. 1995, 95, 69-96. [CrossRef]

16. Pargoletti, E.; Mostoni, S.; Rassu, G.; Pifferi, V.; Meroni, D.; Falciola, L.; Davoli, E.; Marelli, M.; Cappelletti, G. Zn- vs Bi-based oxides for o-toluidine photocatalytic treatment under solar light. Env. Sci. Pollut. Res. 2017, 24, 8287-8296. [CrossRef] 
17. IRSG. International rubber study group Statistical summary of world rubber situation. Rubber Stat. Bull. 2017. Available online: http://www.rubberstudy.com/documents/Sample\%20Report/Sample\%20RSB\%20Report.pdf (accessed on 1 June 2017).

18. Perl, A. Annual Minerals Review. Am. Ceram. Soc. Bull. 1997, 76, 140.

19. International Zinc Association-Zinc Oxide Information Center. Available online: http://www.znoxide.org/ index.html (accessed on 1 April 1997).

20. Moezzi, A.; McDonagh, A.M.; Cortie, M.B. Zinc oxide particles: Synthesis, properties and applications. Chem. Eng. J. 2012, 185, 1-22. [CrossRef]

21. Das, A.; Wang, D.-Y.; Leuteritz, A.; Subramaniam, K.; Greenwell, H.C.; Wagenknecht, U.; Heinrich, G. Preparation of zinc oxide free, transparent rubber nanocomposites using a layered double hydroxide filler. J. Mater. Chem. 2011, 21, 7194. [CrossRef]

22. Cai, G.-R. Redefining Vulcanization. Technol. Cult. 2010, 51, 357-387.

23. Coleman, M.M.; Shelton, J.R.; Koenig, J.L. Sulfur Vulcanization of Hydrocarbon Diene Elastomers. Ind. Eng. Chem. Prod. Res. Dev. 1974, 13, 154-166. [CrossRef]

24. Ducháček, V.; Kuta, A.; Pribyl, P. Efficiency of metal activators of accelerated sulfur vulcanization. J. Appl. Polym. Sci. 1993, 47, 743-746. [CrossRef]

25. Heideman, G. Reduced Zinc Oxide Levels in Sulphur Vulcanisation of Rubber Compounds. Ph.D. Thesis, University of Twente, Enschede, The Netherlands, 2004.

26. Krejsa, M.R.; Koenig, J.L. A Review of Sulfur Crosslinking Fundamentals for Accelerated and Unaccelerated Vulcanization. Rubber Chem. Technol. 1993, 66, 376-410. [CrossRef]

27. Morrison, N.J.; Porter, M. Temperature effects on the stability of intermediates and crosslinks in sulfur vulcanization. Rubber Chem. Technol. 1984, 57, 63-85. [CrossRef]

28. Councell, T.B.; Duckenfield, K.U.; Landa, E.R.; Callender, E. Tire-wear particles as a source of zinc to the environment. Environ. Sci. Technol. 2004, 38, 4206-4214. [CrossRef]

29. Callender, E.; Rice, K.C. The urban environmental gradient: Anthropogenic influences on the spatial and temporal distributions of lead and zinc in sediments. Environ. Sci. Technol. 2000, 34, 232-238. [CrossRef]

30. Santa Clara Valley Nonpoint Source Control Program. Santa Clara Valley Nonpoint Source Control Program, Source Identification and Control Report; Woodward-Clyde Consultants: Santa Clara, CA, USA, 1992.

31. Wolfenden, L. Tyres Report; British Energy Agency: London, UK, 2001.

32. Lander, L.; Lindström, L. Zinc in Society and the Environment: An Account of the Facts on Fluxes, Amounts and Effects of Zinc in Sweden; Swedish Environmental Research Group: Fryksta, Sweden, 1998.

33. EPA. Environmental Protection Agency National Recommended Water Qaulity Criteria; EPA: Washington, DC, USA, 1999.

34. EPA. Environmental Protection Agency National Secondary Drinking Water Regulations; EPA: Washington, DC, USA, 1984.

35. Ramos, G.; Alguacil, F.J.; López, F.A. The recycling of end-of-life tyres. Technological review. Rev. Metal. 2011, 47, 273-284.

36. Eldin, N.N.; Senouci, A.B. Rubber-tire particles as concrete aggregate. J. Mater. Civ. Eng. 1993, 5, 478-496. [CrossRef]

37. Heideman, G.; Noordermeer, J.W.M.; Datta, R.N.; Van Baarle, B. Effect of metal oxides as activator for sulphur vulcanisation in various rubbers. KGK Kautsch. Gummi Kunstst. 2005, 58, 30-42.

38. Lautenschlaeger, F.K.; Edwards, K. Model compound vulcanization-Part V. The effect of chemical additives and fillers. Rubber Chem. Technol. 1980, 53, 27-47. [CrossRef]

39. Guzmán, M.; Vega, B.; Agulló, N.; Giese, U.; Borrós, S. Zinc oxide versus magnesium oxide revisited. Part 1. Rubber Chem. Technol. 2012, 85, 38-55. [CrossRef]

40. Scotti, R.; D'Arienzo, M.; Di Credico, B.; Giannini, L.; Morazzoni, F. Silica-Polymer Interface and Mechanical Reinforcement in Rubber Nanocomposites. In Hybrid Organic-Inorganic Interfaces: Towards Advanced Functional Materials; Wiley: Hoboken, NJ, USA, 2018.

41. Barlow, C.; Jayasuriya, S.; Suan Tan, C. The World Rubber Industry; Routledge Revivals: Abingdon, UK, 1994.

42. Garcés, J.M.; Moll, D.J.; Bicerano, J.; Fibiger, R.; McLeod, D.G. Polymeric nanocomposites for automotive applications. Adv. Mater. 2000, 12, 1835-1839. [CrossRef]

43. Donnet, J.B. Nano and microcomposites of polymers elastomers and their reinforcement. Compos. Sci. Technol. 2003, 63, 1085-1088. [CrossRef] 
44. Di Credico, B.; Cobani, E.; Callone, E.; Conzatti, L.; Cristofori, D.; D'Arienzo, M.; Dirè, S.; Giannini, L.; Hanel, T.; Scotti, R.; et al. Size-controlled self-assembly of anisotropic sepiolite fibers in rubber nanocomposites. Appl. Clay Sci. 2018, 152, 51-64. [CrossRef]

45. Di Credico, B.; Tagliaro, I.; Cobani, E.; Conzatti, L.; D’Arienzo, M.; Giannini, L.; Mascotto, S.; Scotti, R.; Stagnaro, P.; Tadiello, L. A Green Approach for Preparing High-Loaded Sepiolite/Polymer Biocomposites. Nanomaterials 2018, 9, 46. [CrossRef]

46. D'Arienzo, M.; Diré, S.; Redaelli, M.; Borovin, E.; Callone, E.; Di Credico, B.; Morazzoni, F.; Pegoretti, A.; Scotti, R. Unveiling the hybrid interface in polymer nanocomposites enclosing silsesquioxanes with tunable molecular structure: Spectroscopic, thermal and mechanical properties. J. Colloid Interface Sci. 2018, 512, 609-617. [CrossRef]

47. Redaelli, M.; D’Arienzo, M.; Brus, J.; Di Credico, B.; Geppi, M.; Giannini, L.; Matejka, L.; Martini, F.; Panattoni, F.; Spirkova, M.; et al. On the key role of $\mathrm{SiO}_{2} @ P O S S$ hybrid filler in tailoring networking and interfaces in rubber nanocomposites. Polym. Test. 2018, 65, 429-439. [CrossRef]

48. Spence, D.; Ferry, J.D. Enhanced Polymerization and Depolymerization of Natural Rubber by Quinones and Related Compounds. Rubber Chem. Technol. 2011, 11, 47-56. [CrossRef]

49. Scott, K.W.; Lorenz, O.; Parks, C.R. Network degradation accompanying the vulcanization of natural rubber with a sulfur-diphenylguanidine system. J. Appl. Polym. Sci. 1964, 8, 2909-2922. [CrossRef]

50. Ghosh, P.; Katare, S.R.; Patkar, P.R.; Caruthers, J.M.; Venkatasubramanian, V.; Walker, K.A. Sulfur Vulcanization of Natural Rubber for Benzothiazole Accelerated Formulations: From reaction mechanisms to a rational kinetic model. Rubber Chem. Technol. 2003, 76, 592-693. [CrossRef]

51. Reddy, C.M.; Quinn, J.G. Environmental chemistry of benzothiazeles derived from rubber. Environ. Sci. Technol. 1997, 31, 2847-2853. [CrossRef]

52. Aprem, A.S.; Joseph, K.; Mathew, T.; Altstaedt, V.; Thomas, S. Studies on accelerated sulphur vulcanization of natural rubber using 1-phenyl-2, 4-dithiobiuret/tertiary butyl benzothiazole sulphenamide. Eur. Polym. J. 2003, 39, 1451-1460. [CrossRef]

53. Nieuwenhuizen, P.J.; Reedijk, J.; van Duin, M.; McGill, W.J. Thiuram and Dithiocarbamate-Accelerated Sulfur Vulcanization from the Chemist's Perspective; Methods, Materials and Mechanisms Reviewed. Rubber Chem. Technol. 2011, 70, 368-429. [CrossRef]

54. Hernández, M.; Ezquerra, T.A.; Verdejo, R.; López-Manchado, M.A. Role of vulcanizing additives on the segmental dynamics of natural rubber. Macromolecules 2012, 45, 1070-1075. [CrossRef]

55. Wolfe, J.R.; Pugh, T.L.; Killian, A.S. The Chemistry of Sulfur Curing. III. Effects of Zinc Oxide on the Mechanism of the Reaction of Cyclohexene with Sulfur. Rubber Chem. Technol. 2011, 41, 1329-1338. [CrossRef]

56. Isayev, A.I.; Deng, J.S. Nonisothermal vulcanization of rubber compounds. Rubber Chem. Technol. 1987, 61, 340-361. [CrossRef]

57. Ding, R.; Lenov, A.I.; Coran, A.Y. study of the vulcanization kinetics of an accelerated-sulfur SBR compound. Rubber Chem. Technol. 1995, 69, 81-91. [CrossRef]

58. Milani, G.; Leroy, E.; Milani, F.; Deterre, R. Mechanistic modeling of reversion phenomenon in sulphur cured natural rubber vulcanization kinetics. Polym. Test. 2013, 32, 1052-1063. [CrossRef]

59. Milani, G.; Milani, F. Closed form numerical approach for a kinetic interpretation of high-cis polybutadiene rubber vulcanization with sulphur. J. Math. Chem. 2017, 55, 552-583. [CrossRef]

60. Mathew, A.P.; Packirisamy, S.; Thomas, S. Studies on the thermal stability of natural rubber/polystyrene interpenetrating polymer networks: Thermogravimetric analysis. Polym. Degrad. Stab. 2001, 72, 423-439. [CrossRef]

61. Tiwari, M.; Noordermeer, J.W.M.; Dierkes, W.K.; van Ooij, W.J. Effect of Plasma Polymerization on the Performance of Silica in NBR, EPDM and NBR/EPDM Blends. Rubber Chem. Technol. 2011, 81, $276-296$. [CrossRef]

62. Coran, A.Y. Vulcanization. Part V. The formation of crosslinks in the system: Natural rubber-sulfur-MBT-zinc ion. Rubber Chem. Technol. 1964, 37, 679-688. [CrossRef]

63. Norvez, S.; Ikeda, Y.; Higashitani, N.; Hijikata, K.; Kokubo, Y.; Morita, Y.; Shibayama, M.; Osaka, N.; Suzuki, T.; Endo, H.; et al. Vulcanization: New focus on a traditional technology by small-angle neutron scattering. Macromolecules 2009, 42, 2741-2748. 
64. Van den Berg, J.H.M.; Beulen, J.W.; Duynstee, E.F.J.; Nelissen, H.L. Model Vulcanization of EPDM Compounds-Part I: Structure Determination of Vulcanization Products from Ethylidene Norbornane. Rubber Chem. Technol. 1984, 57, 265-274. [CrossRef]

65. Fujimoto, K.; Wataya, K. The study of polymers by high-temperature ATR spectroscopy. J. Appl. Polym. Sci. 1969, 13, 2513-2526. [CrossRef]

66. Armstrong, R.T.; Little, J.R.; Doak, K.W. Chemistry of Sulfur-Olefin Reactions. Ind. Eng. Chem. 1944, 36, 628-633. [CrossRef]

67. Choi, W. The Main Mechanism and Cross-Linking Structure for Accelerated Sulfur Vulcanization. e-J. Soft Mater. 2006, 2, 47-55. [CrossRef]

68. Nieuwenhuizen, P.J.; Sandjaj, T.; Van Veen, J.M. Homogeneous zinc (II) catalysis in accelerated vulcanization I. Reaction-stage modeling and cross-link formation. Rubber Chem. Technol. 1998, 71, 750-765. [CrossRef]

69. Damen, R.; Nieuwenhuizen, P.J.; Haasnoot, J.G.; Reedijk, J.; Couchman, S.M.; Jeffery, J.; McCleverty, J.A. Homogeneous zinc (II) catalysis in accelerated vulcanization: IV. The prevailing mechanism of crosslink formation in mercaptobenzothiazole systems. Rubber Chem. Technol. 2003, 76, 82-100. [CrossRef]

70. Hahn, J.; Palloch, P.; Thelen, N.; Weidenhaupt, H.-J. Reversion Stable Networks with Polysulfide Polymers as Vulcanization Agents. Rubber Chem. Technol. 2011, 74, 28-43. [CrossRef]

71. Heideman, G.; Datta, R.N.; Noordermeer, J.W.M.; Van Baarle, B. Influence of zinc oxide during different stages of sulfur vulcanization. elucidated by model compound studies. J. Appl. Polym. Sci. 2005, 95, 1388-1404. [CrossRef]

72. Heideman, G.; Datta, R.N.; Noordermeer, J.W.M.; Van Baarle, B. Activators in Accelerated Sulfur Vulcanization. Rubber Chem. Technol. 2004, 77, 512-541. [CrossRef]

73. Ignatz-Hoover, F. Review of vulcanization chemistry. Rubber World 1999, 220.

74. Chapman, A.V. The influence of excess zinc stearate on the chemistry of sulphur vulcanization of natural rubber. Phosphorus Sulfur Silicon Relat. Elem. 1991, 59, 271-274. [CrossRef]

75. Heideman, G.; Noordermeer, J.W.M.; Datta, R.N.; van Baarle, B. Multifunctional Additives as Zinc-Free Curatives for Sulfur Vulcanization. Rubber Chem. Technol. 2006, 79, 561-588. [CrossRef]

76. Versloot, P.; Haasnoot, J.G.; Nieuwenhuizen, P.J.; Reedijk, J.; van Duin, M.; Put, J. Sulfur Vulcanization of Simple Model Olefins, Part V: Double Bond Isomerization during Accelerated Sulfur Vulcanization as Studied by Model Olefins. Rubber Chem. Technol. 2011, 70, 106-119. [CrossRef]

77. Mcgill, W.J.; Shelver, S.R. Effect of carboxylic acids on 2-bisbenzothiazole-2,2'-disulfide- and tetramethylthiuram disulfide-accelerated sulfur vulcanization. II. Vulcanization of polyisoprene in the absence of ZnO. J. Appl. Polym. Sci. 1999, 72, 1007-1012. [CrossRef]

78. Ikeda, Y.; Yasuda, Y.; Ohashi, T.; Yokohama, H.; Minoda, S.; Kobayashi, H.; Honma, T. Dinuclear bridging bidentate zinc/stearate complex in sulfur cross-linking of rubber. Macromolecules 2015, 48, 462-475. [CrossRef]

79. Coran, A.Y. Chemistry of the vulcanization and protection of elastomers: A review of the achievements. J. Appl. Polym. Sci. 2003, 87, 24-30. [CrossRef]

80. Morgan, B.; Mcgill, W.J. 2-Mercaptobenzothiazole as Accelerator for 2, 3-Dimethyl-2-butene. J. Appl. Polym. Sci. 2000, 76, 1377-1385. [CrossRef]

81. Gradwell, M.H.S.; Van Der Merwe, M.J. 2- t butylbenzothiazole sulfenamide accelerated sulfur vulcanization of polyisoprene. Rubber Chem. Technol. 1999, 72, 55-64. [CrossRef]

82. Farmer, E.H.; Shipley, F.W. The Reaction of Sulphur and Sulphur Compounds with Olefinic Substances. Part I. The reaction of Sulphur with mono-olefins and with 1:5-diolefins. J. Chem. Soc. 1947, 298, 1519-1532. [CrossRef]

83. Bateman, L.; Moore, C.G.; Porter, M. The Reaction of Sulphur and Sulphur Compounds with Olefinic substances. Part XI. The Mechanim of Interaction of Sulphur with Mono-olefins and 1: 5-Dienes. J. Chem. Soc. 1958, 2866-2879. [CrossRef]

84. Sadequl, A.M.; Ishiaku, U.S.; Ismail, H.; Poh, B.T. The effect of accelerator/sulphur ratio on the scorch time of epoxidized natural rubber. Eur. Polym. J. 1998, 34, 51-57. [CrossRef]

85. Poh, B.T.; Tang, W.L. Concentration effect of stearic acid on scorch behavior of epoxidized natural rubber. J. Appl. Polym. Sci. 1995, 55, 537-542. [CrossRef]

86. Susanna, A.; D’Arienzo, M.; Di Credico, B.; Giannini, L.; Hanel, T.; Grandori, R.; Morazzoni, F.; Mostoni, S.; Santambrogio, C.; Scotti, R. Catalytic effect of $\mathrm{ZnO}$ anchored silica nanoparticles on rubber vulcanization and cross-link formation. Eur. Polym. J. 2017, 93, 63-74. [CrossRef] 
87. Roy, K.; Alam, M.N.; Mandal, S.K.; Debnath, S.C. Preparation of zinc-oxide-free natural rubber nanocomposites using nanostructured magnesium oxide as cure activator. J. Appl. Polym. Sci. 2015, 132, 1-7. [CrossRef]

88. Guzmán, M.; Vega, B.; Agulló, N.; Borrós, S. Zinc Oxide Versus Magnesium Oxide Revisited. Part 2. Rubber Chem. Technol. 2012, 85, 56-67. [CrossRef]

89. Sahoo, S.; Maiti, M.; Ganguly, A.; George, J.J.; Bhowmick, A.K. Effect of zinc oxide nanoparticles as cure activator on the properties of natural rubber and nitrile rubber. J. Appl. Polym. Sci. 2007, 105, 2407-2415. [CrossRef]

90. Przybyszewska, M.; Zaborski, M. The effect of zinc oxide nanoparticle morphology on activity in crosslinking of carboxylated nitrile elastomer. Express Polym. Lett. 2009, 3, 542-552. [CrossRef]

91. Panampilly, B.; Thomas, S. Nano ZnO as Cure activator and reinforcing filler in natural rubber. Polym. Eng. Sci. 2013, 53, 1337-1346. [CrossRef]

92. Tan, E.-H.; Wolff, S.; Haddeman, M.; Grewatta, H.P.; Wang, M.-J. Filler-Elastomer interactions. Part IX. Performance of silicas in polar elastomers. Rubber Chem. Technol. 1993, 66, 594-604. [CrossRef]

93. Roy, K.; Alam, M.N.; Mandal, S.K.; Debnath, S.C. Sol-gel derived nano zinc oxide for the reduction of zinc oxide level in natural rubber compounds. J. Sol Gel Sci. Technol. 2014, 70, 378-384. [CrossRef]

94. Cui, J.; Zhang, L.; Wu, W.; Cheng, Z.; Sun, Y.; Jiang, H.; Li, C. Zinc oxide with dominant (1 00 0) facets boosts vulcanization activity. Eur. Polym. J. 2019, 113, 148-154. [CrossRef]

95. Chen, Y.; Kim, M.; Lian, G.; Johnson, M.B.; Peng, X. Side reactions in controlling the quality, yield, and stability of high quality colloidal nanocrystals. J. Am. Chem. Soc. 2005, 127, 13331-13337. [CrossRef]

96. Heideman, G.; Noordermeer, J.W.M.; Datta, R.N.; van Baarle, B. Effect of Zinc Complexes as Activator for Sulfur Vulcanization in Various Rubbers. Rubber Chem. Technol. 2005, 78, 245-257. [CrossRef]

97. Heideman, G.; Noordermeer, J.W.M.; Datta, R.N.; Van Baarle, B. Various ways to reduce zinc oxide levels in S-SBR rubber compounds. Macromol. Symp. 2006, 245, 657-667. [CrossRef]

98. Steudel, R.; Steudel, Y.; Wong, M.W. Complexation of the vulcanization accelerator tetramethylthiuram disulfide and related molecules with zinc compounds including zinc oxide clusters $\left(\mathrm{Zn}_{4} \mathrm{O}_{4}\right)$. Chem. A Eur. J. 2008, 14, 919-932. [CrossRef]

99. Przybyszewska, M.; Zaborski, M.; Jakubowski, B.; Zawadiak, J. Zinc chelates as new activators for sulphur vulcanization of acrylonitrile-butadiene elastomer. Express Polym. Lett. 2009, 3, 256-266. [CrossRef]

100. Alam, M.N.; Mandal, S.K.; Debnath, S.C. Effect of Zinc Dithiocarbamates and Thiazole-Based Accelerators on the Vulcanization of Natural Rubber. Rubber Chem. Technol. 2012, 85, 120-131. [CrossRef]

101. Henning, S.K. Reduced Zinc Loading: Using Zinc Monomethacrylate to Activate Accelerated Sulfur Vulcanization. In Proceedings of the Fall 172nd Technical Meeting of the Rubber Division, American Chemical Society, Cray Valley USA, LLC Exton, Pennsylvania USA, Cleveland, OH, USA, 16 October 2007.

102. Moresco, S.; Giovanela, M.; Carli, L.N.; Crespo, J.S. Development of passenger tire treads: Reduction in zinc content and utilization of a bio-based lubricant. J. Clean. Prod. 2016, 117, 199-206. [CrossRef]

103. Zanchet, A.; De Sousa, F.D.B.; Crespo, J.S.; Scuracchio, C.H. Activator from sugar cane as a green alternative to conventional vulcanization additives. J. Clean. Prod. 2018, 174, 437-446. [CrossRef]

104. Zanchet, A.; Demori, R.; de Sousa, F.D.B.; Ornaghi, H.L.; Schiavo, L.S.A.; Scuracchio, C.H. Sugar cane as an alternative green activator to conventional vulcanization additives in natural rubber compounds: Thermal degradation study. J. Clean. Prod. 2019, 207, 248-260. [CrossRef]

105. Gardiner, B.J. Curative diffusion between dissimilar elastomers and its influence on adhesion. Rubber Chem. Technol. 1968, 41, 1312-1328. [CrossRef]

106. Chen, L.; Guo, X.; Luo, Y.; Jia, Z.; Chen, Y.; Jia, D. Inorganic and Organic Hybrid Nanoparticles as Multifunctional Crosslinkers for Rubber Vulcanization with High-Filler Rubber Interaction. Polymers 2018, 10, 1138. [CrossRef]

107. Chen, L.; Guo, X.; Luo, Y.; Jia, Z.; Bai, J.; Chen, Y.; Jia, D. Effect of novel supported vulcanizing agent on the interfacial interaction and strain-induced crystallization properties of natural rubber nanocomposites. Polymer 2018, 148, 390-399. [CrossRef]

108. Mao, Y.; Tian, Q.; Zhang, C.; Tang, Y.; Wang, Y.; Li, X.; Ding, T. Vulcanization accelerator functionalized nanosilica: Effect on the reinforcement behavior of SSBR/BR. Polym. Eng. Sci. 2019, 59, 1270-1278. [CrossRef] 
109. Zhong, B.; Jia, Z.; Luo, Y.; Jia, D. Surface modification of silica with N-cyclohexyl-2-benzothiazole sulfenamide for styrene-butadiene rubber composites with dramatically improved mechanical property. Mater. Lett. 2015, 145, 41-43. [CrossRef]

110. Zhong, B.; Jia, Z.; Luo, Y.; Jia, D. A method to improve the mechanical performance of styrene-butadiene rubber via vulcanization accelerator modified silica. Compos. Sci. Technol. 2015, 117, 46-53. [CrossRef]

111. Heideman, G.; Noordermeer, J.W.M.; Datta, R.N.; Baarle, B. Van Modified Clays as Activator in Sulphur Vulcanisation. Kautsch. Gummi Kunstst. 2003, 56, 650-656.

112. Heideman, G.; Noordermeer, J.W.M.; Datta, R.N. Zinc Loaded Clay as Activator in Sulfur Vulcanization: A new route for zinc oxide reduction in rubber compounds. Rubber Chem. Technol. 2004, 77, 336-355. [CrossRef]

113. Eshwaran, S.B.; Basu, D.; Kutlu, B.; Leuteritz, A.; Wagenknecht, U.; Stöckelhuber, K.W.; Naskar, K.; Das, A.; Heinrich, G. Stearate Modified Zinc-Aluminum Layered Double Hydroxides and Acrylonitrile Butadiene Rubber Nanocomposites. Polym. Plast. Technol. Eng. 2014, 53, 65-73. [CrossRef]

114. Qi, J.Y.; Wu, L.X.; Zhuo, D.X. Preparation and Properties of BR/SBR Blends Using Surface-Modified Nano Zinc Oxide. Adv. Mater. Res. 2014, 910, 101-104. [CrossRef]

115. Gujel, A.A.; Bandeira, M.; Menti, C.; Perondi, D.; Guégan, R.; Roesch-Ely, M.; Giovanela, M.; Crespo, J.S. Evaluation of vulcanization nanoactivators with low zinc content: Characterization of zinc oxides, cure, physico-mechanical properties, $\mathrm{Zn} 2+$ release in water and cytotoxic effect of EPDM compositions. Polym. Eng. Sci. 2018, 58, 1800-1809. [CrossRef]

116. Niemantsverdriet, J.W.; Chorkendorff, I. Concept of Modern Catalysis and Kinetics; WILEY-VCH Verlag GmbH \& Co.: Weinheim, Germany, 2003.

117. Murata, K.; Mahara, Y.; Ohyama, J.; Yamamoto, Y.; Arai, S.; Satsuma, A. The Metal-Support Interaction Concerning the Particle Size Effect of Pd/Al2O3 on Methane Combustion. Angew. Chem. 2017, 129, 16209-16213. [CrossRef]

118. Kuo, T.J.; Lin, C.N.; Kuo, C.L.; Huang, M.H. Growth of ultralong ZnO nanowires on silicon substrates by vapor transport and their use as recyclable photocatalysts. Chem. Mater. 2007, 19, 5143-5147. [CrossRef]

119. Mihai, G.D.; Meynen, V.; Mertens, M.; Bilba, N.; Cool, P.; Vansant, E.F. ZnO nanoparticles supported on mesoporous MCM-41 and SBA-15: A comparative physicochemical and photocatalytic study. J. Mater. Sci. 2010, 45, 5786-5794. [CrossRef]

120. Ren, Y.; Zhang, F.; Hua, W.; Yue, Y.; Gao, Z. ZnO supported on high silica HZSM-5 as new catalysts for dehydrogenation of propane to propene in the presence of $\mathrm{CO}_{2}$. Catal. Today 2009, 148, 316-322. [CrossRef]

121. Susanna, A.; Armelao, L.; Callone, E.; Dirè, S.; D'Arienzo, M.; Di Credico, B.; Giannini, L.; Hanel, T.; Morazzoni, F.; Scotti, R. ZnO nanoparticles anchored to silica filler. A curing accelerator for isoprene rubber composites. Chem. Eng. J. 2015, 275, 245-252. [CrossRef]

122. Acikgoz, C.; Sahbaz, D.A.; Kockar, O.M. ZnO nanoparticles bonded to $\mathrm{SiO}_{2}$ filler as a curing accelerator in cold vulcanizing adhesives. Acta Phys. Pol. A 2017, 131, 200-203. [CrossRef]

123. Alam, M.N.; Potiyaraj, P. Precipitated Nano Zinc Hydroxide on the Silica Surface as an Alternative Cure Activator in the Vulcanization of Natural Rubber. Rubber Chem. Technol. 2017, 90, 714-727. [CrossRef]

124. Lin, Y.; Zeng, Z.; Zhu, J.; Chen, S.; Yuan, X.; Liu, L. Graphene nanosheets decorated with ZnO nanoparticles: Facile synthesis and promising application for enhancing the mechanical and gas barrier properties of rubber nanocomposites. RSC Adv. 2015, 5, 57771-57780. [CrossRef]

125. Li, Y.; Sun, H.; Zhang, Y.; Xu, M.; Shi, S.Q. The three-dimensional heterostructure synthesis of ZnO/cellulosic fibers and its application for rubber composites. Compos. Sci. Technol. 2019, 177, 10-17. [CrossRef]

(C) 2019 by the authors. Licensee MDPI, Basel, Switzerland. This article is an open access article distributed under the terms and conditions of the Creative Commons Attribution (CC BY) license (http://creativecommons.org/licenses/by/4.0/). 